\title{
Flex-16: A Large-Displacement Monolithic Compliant Rotational Hinge
}

Robert Mclntyre Fowler

Brigham Young University - Provo

Alex Maselli

Peter Pluimers

Spencer P. Magleby

Larry L. Howell

Brigham Young University - Utah, Ihowell@byu.edu

Follow this and additional works at: https://scholarsarchive.byu.edu/facpub

Part of the Mechanical Engineering Commons

\section{BYU ScholarsArchive Citation}

Fowler, Robert McIntyre; Maselli, Alex; Pluimers, Peter; Magleby, Spencer P.; and Howell, Larry L., "Flex-16: A Large-Displacement Monolithic Compliant Rotational Hinge" (2014). Faculty Publications. 1554. https://scholarsarchive.byu.edu/facpub/1554 accepted for inclusion in Faculty Publications by an authorized administrator of BYU ScholarsArchive. For more information, please contact ellen_amatangelo@byu.edu. 


\title{
Flex-16: \\ A Large-Displacement Monolithic Compliant Rotational Hinge
}

\author{
Robert M Fowler ${ }^{\mathrm{a}}$, Alex Masellia ${ }^{\mathrm{a}}$, Pieter Pluimers ${ }^{\mathrm{b}}$, Spencer P Magleby ${ }^{\mathrm{a}}$, \\ Larry L Howell ${ }^{\mathrm{a}, *}$ \\ ${ }^{a}$ Department of Mechanical Engineering \\ Brigham Young University \\ Provo, UT, U.S.A. 84602 \\ ${ }^{b}$ Mechanical, Maritime and Materials Engineering \\ Delft University of Technology \\ Delft, The Netherlands
}

\begin{abstract}
This paper describes the design, analysis, and testing of a large-displacement monolithic compliant rotational hinge, called the Flex-16. The Flex-16 achieves $90^{\circ}$ of rotation from monolithic construction and is aimed for application as a compliant satellite deployment hinge. Five prototypes were fabricated from three different materials (polypropylene, titanium, and a carbon nanotube framework) on two different size scales (macro and micro). A parametric finite element model was created to rapidly analyze a variety of design identified during a configuration study. Prototypes were tested for their ability to reach $90^{\circ}$ of rotation without failure or self collision, and for their nonlinear rotational stiffness. Natural frequencies, mode shapes, thermal stresses, off-axis stiffness, and parasitic center shift were quantified. Integrated application concepts are presented.
\end{abstract}

Keywords: compliant mechanism, monolithic, hinge, large displacement, deployment, rotational, joint, space mechanism

\footnotetext{
*Corresponding Author

Email address: 1howell@byu.edu (Larry L Howell)
} 


\section{Introduction}

\subsection{Objective}

The objective of this chapter is to describe the design, prototyping, and testing of a monolithic compliant mechanism capable of large rotational displacement for potential use as a compliant spacecraft deployment hinge. It aims to provide a replacement for ball bearings and other lubricated joints in space mechanisms. The mechanism is desired to be capable of at least $90^{\circ}$ of angular displacement and benefit from planar manufacturing methods.

\subsection{Motivation}

Of the many types of space mechanisms, deployment hinges are among the most common and their performance is vital to the objectives of a spacecraft mission. Current deployment hinges exhibit numerous possible failure modes [1]. Many of the failure modes are lubrication and tribology related. The number of failure modes can be reduced by application of compliant mechanism technology to the design of deployment hinges. A largedisplacement monolithic compliant deployment hinge would not be susceptible to lubrication outgassing, cold welding, friction, binding, and backlash [2]. Among other things, it has the potential to eliminate lubrication and rigid-link joints while reducing part count, complexity, and cost. It would increase the ease of manufacturing and integration with the other spacecraft components. It would also increase the ability of the hinge designer to control the stiffness, stresses, and natural frequencies of the hinge and tailor the dynamics of the deploying appendage to meet the mission deployment performance requirements.

Ball bearings are often used in space hinges. They are challenged by the complexities associated with quantifying reliability and performance of a joint whose rotation is dependent on lubrication and contact surfaces in the harsh environments of space. A large-displacement monolithic compliant deployment hinge could be immune to those challenges.

The Flex-16, as depicted in Figure 1, is proposed as a possible alternative to traditional space hinges. Its design, analysis, and testing are detailed in this paper.

\section{Background}

Compliant mechanism hinges [3] have been developed for use in precision devices $[4,5,6,7,8]$, spherical mechanisms [9, 10], lamina emergent mech- 


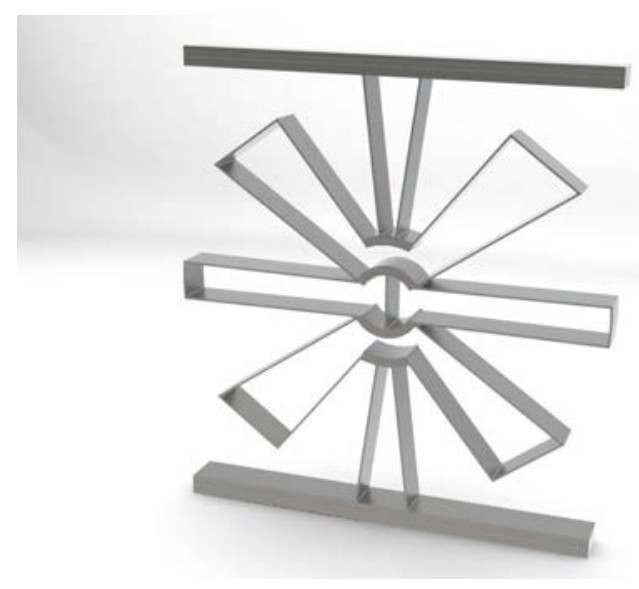

Figure 1: A Flex-16 compliant rotational hinge.

anisms [11, 12], and other applications [13, 14, 15] including some for large deflections $[16,17]$. Several tape spring designs have been presented that can offer large displacement [18, 19, 20, 21].

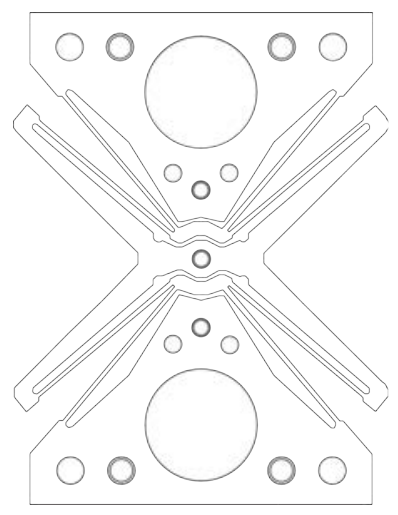

Figure 2: Butterfly Pivot developed by S. Henein et al. [22]

The butterfly pivot developed by Henein et al. [22], as shown in Figure 2 , was designed for precision pointing and had an angular stroke of approximately $15^{\circ}$. It was comprised of 8 flexures, 2 intermediate rigid shuttles, one central X-shaped rigid block, and two rigid ends. This design offered a starting point for the design of a large-displacement compliant rotational hinge.

Significant challenges in creating a monolithic device capable of the de- 
sired large displacement included ensuring that stresses at the maximum deflection did not cause failure, and that the device elements did not collide at any point during the large deflection. Many possible design configurations were evaluated and the Flex-16 design was selected. The following sections describe the Flex-16 and the analysis, prototyping, and testing undergone to arrive at the current design.

\section{Flex-16 Large-Displacement Compliant Rotational Hinge}

\subsection{Hinge Description}

The Flex-16 (Figure 1) is a monolithic large-displacement compliant rotational hinge that is capable of the desired $90^{\circ}$ of rotation. It is comprised of 16 flexures that generally radiate outward from the center of the joint, 4 intermediate rigid shuttles (arc shaped), 1 vertical flexure between the two innermost shuttles, and two rigid ends for fixing the hinge to both the spacecraft and the deploying appendage, as shown in Figure 3.

The Flex-16 is actuated by fixing one rigid end and applying a moment on the other rigid end. The radial flexures allow for large angular displacement by acting in series to divide up the stress and displacement among the individual flexures. The lengths of the flexures are designed to be as long as possible to reduce stresses while still fitting within the size envelope of the hinge and not causing contact between flexures as the hinge displaces. The two innermost intermediate rigid shuttles are connected by a vertical flexure to provide axial stability yet still allow rotation. The outer intermediate rigid shuttles increase stability during rotation and geometrically allow for 4 flexures per quadrant.

\subsection{Hinge Features}

The following list identifies the unique features of the Flex-16 that combine to create a novel mechanism:

- Capable of large-displacement; at least $90^{\circ}$ of rotation

- Monolithic design; only one material needed

- Can be manufactured from planar materials which increases the number of applicable manufacturing processes; planar manufacturing processes often easier and less costly; reduces complexity 


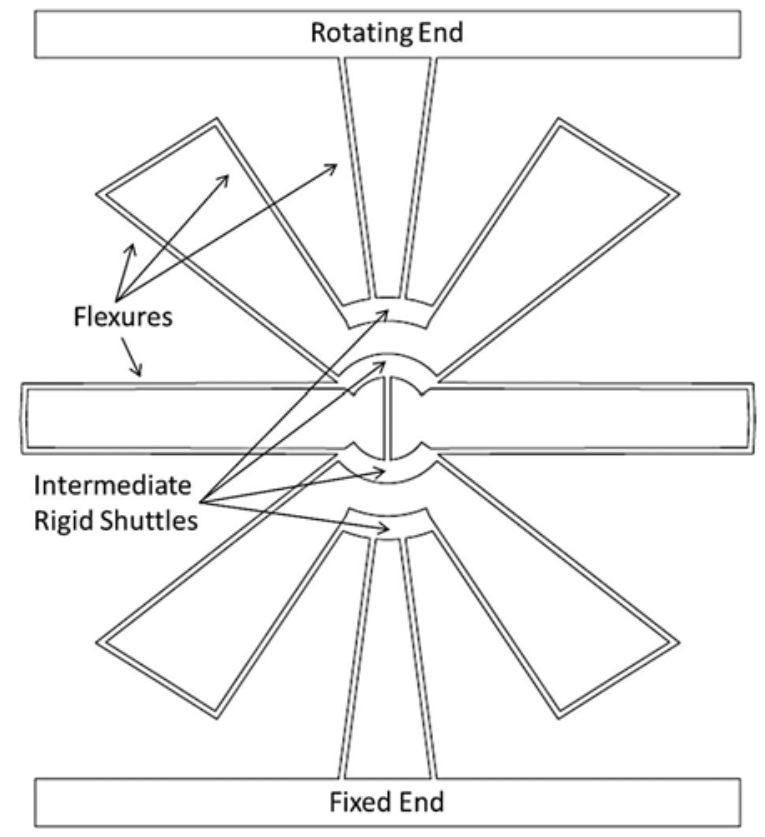

Figure 3: Basic components of Flex-16: 16 radial flexures, 4 intermediate rigid shuttles, 1 vertical flexure, and 2 rigid ends. 
- Low mass; small volume; reduced material cost

- Compact design; smaller size envelope required; hinge capability maximized within its size envelope

- Analysis tools developed to allow development of the hinge on different size scales or using different materials

- Eliminates many current space application failure modes; increases reliability

\section{Parametric Finite Element Model}

A parametric nonlinear finite element model was created in ANSYS for the analysis of the Flex-16. BEAM3 elements were used to allow nonlinear effects and the model contained approximately 1,000 elements. The boundary conditions were fixed on one rigid end and a rotational displacement of $\pi / 2$ radians applied on the other end. The parametric model allowed for iterative design capability to efficiently change and analyze the geometry to improve performance. The finite element model results were evaluated in terms of

- achieving the desired rotational displacement $\left(90^{\circ}\right)$

- ensuring a maximum von Mises stress lower than the material tensile yield strength

- having a displaced shape that does not self-intersect or contact

Knowing the stiffness is important for matching a hinge design to the proper torque loading on the hinge. A Matlab script was created to read in output data from ANSYS and plot the torque-displacement behavior of the hinge designs. This allowed the nonlinear stiffness of the hinge to be quantified. The results from the parametric finite element model are summarized in Section 6.

The parametric finite element model geometry is defined by 47 keypoints, as labeled in Figure 4. Each keypoint is defined in polar coordinates by an angle from the vertical and a fraction of the radius, called the length factor. The angles and length factors are shown for one quadrant of the hinge in Figures 5(a) and 5(b), respectively.

The equations for the Cartesian coordinate locations of each keypoint are listed in Table 1. This allows the user to easily use the model by specifying 


\section{Keypoints}

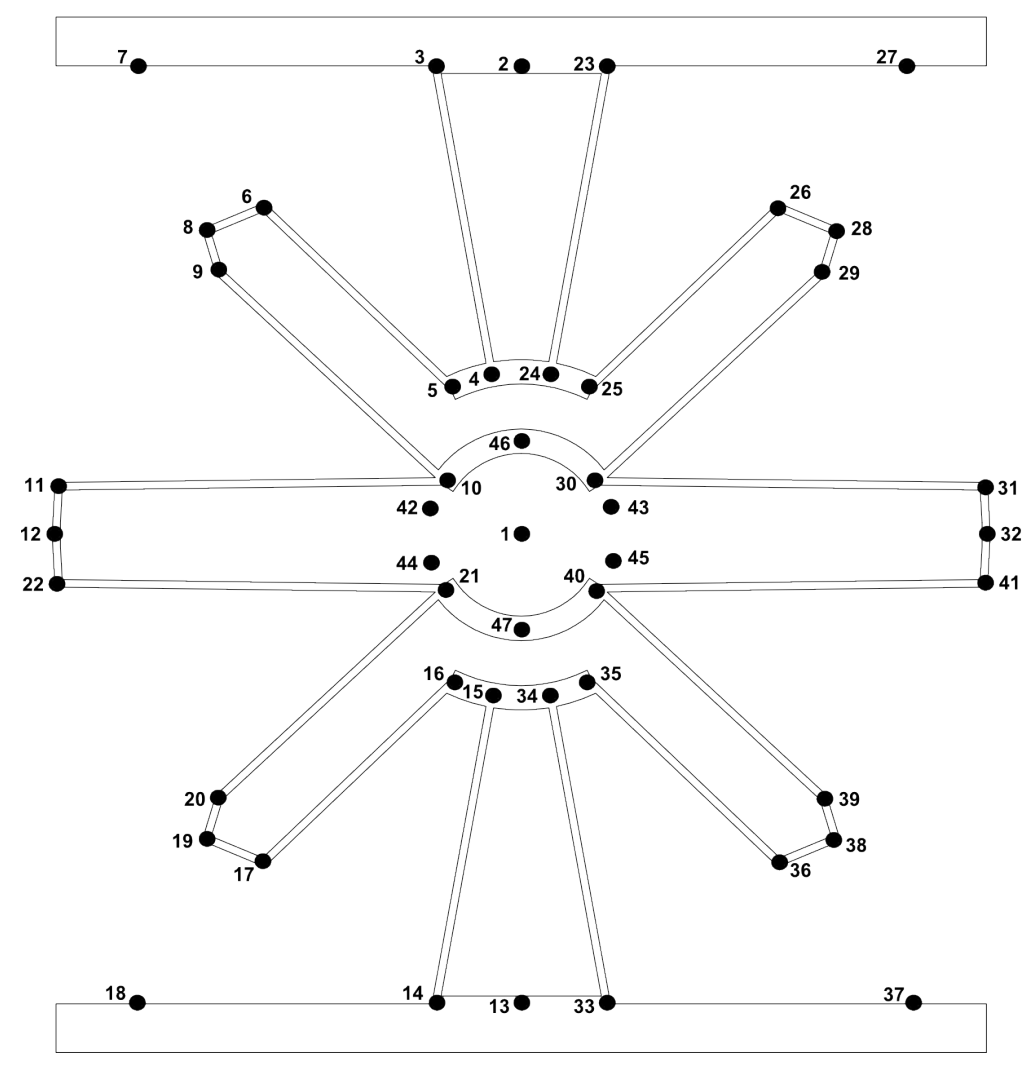

Figure 4: Keypoints used in parametric finite element models. 
Table 1: Keypoint equations

\begin{tabular}{|c|c|c|c|c|c|}
\hline Keypoint & $\mathrm{X}$ Coordinate & Y Coordinate & Keypoint & X Coordinate & Y Coordinate \\
\hline $\mathrm{k} 1$ & 0 & 0 & $\mathrm{k} 25$ & $\mathrm{f} 2^{*} \mathrm{R}^{*} \sin (\mathrm{a} 2)$ & $\mathrm{f} 2^{*} \mathrm{R}^{*} \cos (\mathrm{a} 2)$ \\
\hline $\mathrm{k} 2$ & 0 & $\mathrm{R}$ & $\mathrm{k} 26$ & $\mathrm{f} 3^{*} \mathrm{R}^{*} \sin (\mathrm{a} 3)$ & $\mathrm{f} 3^{*} \mathrm{R}^{*} \cos (\mathrm{a} 3)$ \\
\hline k3 & $-\mathrm{f} 1^{*} \mathrm{R}^{*} \sin (\mathrm{a} 1)$ & $\mathrm{R}$ & $\mathrm{k} 27$ & $\mathrm{f} 4^{*} \mathrm{R}^{*} \sin (\mathrm{a} 3)$ & $\mathrm{R}$ \\
\hline $\mathrm{k} 4$ & $-\mathrm{f} 2 * \mathrm{R}^{*} \sin (\mathrm{a} 1)$ & $\mathrm{f} 2^{*} \mathrm{R}^{*} \cos (\mathrm{a} 1)$ & $\mathrm{k} 28$ & $\mathrm{f5} \mathrm{R}^{*} \sin (\mathrm{a} 4)$ & $\mathrm{f} 5^{*} \mathrm{R}^{*} \cos (\mathrm{a} 4)$ \\
\hline $\mathrm{k} 5$ & $-\mathrm{f} 2 * \mathrm{R}^{*} \sin (\mathrm{a} 2)$ & $\mathrm{f} 2^{*} \mathrm{R}^{*} \cos (\mathrm{a} 2)$ & $\mathrm{k} 29$ & $\mathrm{f} 6^{*} \mathrm{R}^{*} \sin (\mathrm{a} 5)$ & $\mathrm{f} 6^{*} \mathrm{R}^{*} \cos (\mathrm{a} 5)$ \\
\hline k6 & $-\mathrm{f} 3^{*} \mathrm{R}^{*} \sin (\mathrm{a} 3)$ & $\mathrm{f} 3^{*} \mathrm{R}^{*} \cos (\mathrm{a} 3)$ & k30 & $\mathrm{f} 7^{*} \mathrm{R}^{*} \sin (\mathrm{a} 6)$ & $\mathrm{f} 7^{*} \mathrm{R}^{*} \cos (\mathrm{a} 6)$ \\
\hline $\mathrm{k} 7$ & $-\mathrm{f} 4^{*} \mathrm{R}^{*} \sin (\mathrm{a} 4)$ & $\mathrm{R}$ & k31 & $\mathrm{f} 8^{*} \mathrm{R}^{*} \sin (\mathrm{a} 7)$ & $\mathrm{f} 8^{*} \mathrm{R}^{*} \cos (\mathrm{a} 7)$ \\
\hline k8 & $-f 5^{*} \mathrm{R}^{*} \sin (\mathrm{a} 4)$ & $\mathrm{f} 5^{*} \mathrm{R}^{*} \cos (\mathrm{a} 4)$ & k32 & $\mathrm{f} 8^{*} \mathrm{R}$ & 0 \\
\hline k9 & $-f 6^{*} R^{*} \sin (a 5)$ & $\mathrm{f} 6^{*} \mathrm{R}^{*} \cos (\mathrm{a} 5)$ & $\mathrm{k} 33$ & $\mathrm{f} 1 * \mathrm{R}^{*} \sin (\mathrm{a} 1)$ & $-\mathrm{R}$ \\
\hline k10 & $-\mathrm{f}^{*} \mathrm{R}^{*} \sin (\mathrm{a} 6)$ & $\mathrm{f} 7^{*} \mathrm{R}^{*} \cos (\mathrm{a} 6)$ & k34 & $\mathrm{f} 2^{*} \mathrm{R}^{*} \sin (\mathrm{a} 1)$ & $-\mathrm{f} 2^{*} \mathrm{R}^{*} \cos (\mathrm{a} 1)$ \\
\hline k11 & $-\mathrm{f}^{*} \mathrm{R}^{*} \sin (\mathrm{a} 7)$ & $\mathrm{f} 8^{*} \mathrm{R}^{*} \cos (\mathrm{a} 7)$ & k35 & $\mathrm{f} 2^{*} \mathrm{R}^{*} \sin (\mathrm{a} 2)$ & $-\mathrm{f} 2 * \mathrm{R}^{*} \cos (\mathrm{a} 2)$ \\
\hline k12 & $-f 8^{*} \mathrm{R}$ & 0 & $\mathrm{k} 36$ & $\mathrm{f} 3^{*} \mathrm{R}^{*} \sin (\mathrm{a} 3)$ & $-\mathrm{f} 3^{*} \mathrm{R}^{*} \cos (\mathrm{a} 3)$ \\
\hline k13 & 0 & $-\mathrm{R}$ & $\mathrm{k} 37$ & $\mathrm{f} 4^{*} \mathrm{R}^{*} \sin (\mathrm{a} 3)$ & $-\mathrm{R}$ \\
\hline k14 & $-\mathrm{f} 1^{*} \mathrm{R}^{*} \sin (\mathrm{a} 1)$ & $-\mathrm{R}$ & k38 & $\mathrm{f} 5^{*} \mathrm{R}^{*} \sin (\mathrm{a} 4)$ & $-f 5^{*} R^{*} \cos (a 4)$ \\
\hline k15 & $-\mathrm{f} 2 * \mathrm{R}^{*} \sin (\mathrm{a} 1)$ & $-f 2 * R^{*} \cos (a 1)$ & k39 & $\mathrm{f}^{*} \mathrm{R}^{*} \sin (\mathrm{a} 5)$ & $-\mathrm{f} 6^{*} \mathrm{R}^{*} \cos (\mathrm{a} 5)$ \\
\hline k16 & $-\mathrm{f} 2 * \mathrm{R}^{*} \sin (\mathrm{a} 2)$ & $-f 2^{*} R^{*} \cos (a 2)$ & $\mathrm{k} 40$ & $\mathrm{f} 7^{*} \mathrm{R}^{*} \sin (\mathrm{a} 6)$ & $-\mathrm{f} 7^{*} \mathrm{R}^{*} \cos (\mathrm{a} 6)$ \\
\hline k17 & $-\mathrm{f} 3{ }^{*} \mathrm{R}^{*} \sin (\mathrm{a} 3)$ & $-\mathrm{f} 33^{*} \mathrm{R}^{*} \cos (\mathrm{a} 3)$ & $\mathrm{k} 41$ & $\mathrm{f} 8^{*} \mathrm{R}^{*} \sin (\mathrm{a} 7)$ & $-\mathrm{f} 8^{*} \mathrm{R}^{*} \cos (\mathrm{a} 7)$ \\
\hline $\mathrm{k} 18$ & $-\mathrm{f} 4^{*} \mathrm{R}^{*} \sin (\mathrm{a} 3)$ & $-\mathrm{R}$ & $\mathrm{k} 42$ & $-\mathrm{f}^{*} \mathrm{R}^{*} \sin (\mathrm{a} 7)$ & $\mathrm{f} 7^{*} \mathrm{R}^{*} \cos (\mathrm{a} 7)$ \\
\hline k19 & $-f 5^{*} \mathrm{R}^{*} \sin (\mathrm{a} 4)$ & $-f 5^{*} \mathrm{R}^{*} \cos (\mathrm{a} 4)$ & $\mathrm{k} 43$ & $\mathrm{f} 7^{*} \mathrm{R}^{*} \sin (\mathrm{a} 7)$ & $\mathrm{f} 7^{*} \mathrm{R}^{*} \cos (\mathrm{a} 7)$ \\
\hline k20 & $-\mathrm{f} 6{ }^{*} \mathrm{R}^{*} \sin (\mathrm{a} 5)$ & $-\mathrm{f} 66^{*} \mathrm{R}^{*} \cos (\mathrm{a} 5)$ & $\mathrm{k} 44$ & $-\mathrm{f}^{*} \mathrm{R}^{*} \sin (\mathrm{a} 7)$ & $-\mathrm{f} 7^{*} \mathrm{R}^{*} \cos (\mathrm{a} 7)$ \\
\hline $\mathrm{k} 21$ & $-\mathrm{f}^{*} \mathrm{R}^{*} \sin (\mathrm{a} 6)$ & $-\mathrm{f}^{*} \mathrm{R}^{*} \cos (\mathrm{a} 6)$ & $\mathrm{k} 45$ & $\mathrm{f} 7^{*} \mathrm{R}^{*} \sin (\mathrm{a} 7)$ & $-\mathrm{f} 7^{*} \mathrm{R}^{*} \cos (\mathrm{a} 7)$ \\
\hline $\mathrm{k} 22$ & $-\mathrm{f}^{*} \mathrm{R}^{*} \sin (\mathrm{a} 7)$ & $-f 8^{*} R^{*} \cos (a 7)$ & $\mathrm{k} 46$ & 0 & $\mathrm{f} 7 * \mathrm{R}$ \\
\hline $\mathrm{k} 23$ & $\mathrm{f} 1^{*} \mathrm{R}^{*} \sin (\mathrm{a} 1)$ & $\mathrm{R}$ & $\mathrm{k} 47$ & 0 & $-\mathrm{f} 7^{*} \mathrm{R}$ \\
\hline $\mathrm{k} 24$ & $\mathrm{f} 2^{*} \mathrm{R}^{*} \sin (\mathrm{a} 1)$ & $\mathrm{f} 2^{*} \mathrm{R}^{*} \cos (\mathrm{a} 1)$ & & & \\
\hline
\end{tabular}




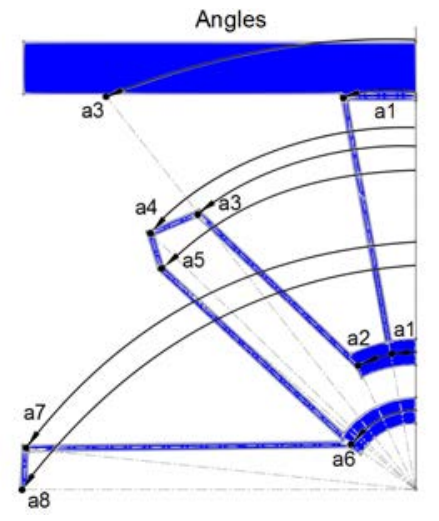

(a) Angles for Defining Keypoints

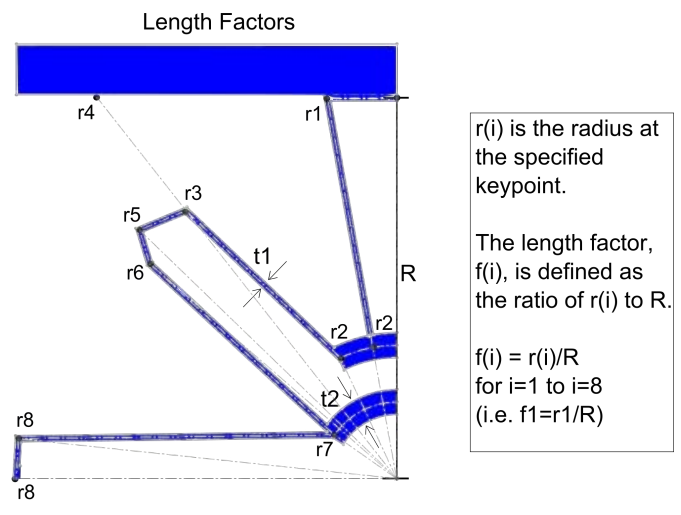

(b) Length Factors for Defining Keypoints

Figure 5: The geometry of the Flex-16 is comprised of keypoints defined by (a) angles and (b) length factors.

the locations of all 47 keypoints using only the radius, eight angles, and eight length factors. The model inputs the keypoints into ANSYS and CAD software in Cartesian coordinates as required. The model facilitates rapid translation of design concepts into finite element models.

These parameters and equations constitute the parametric design and allow the geometry to be changed quickly to iterate on the design. This allows the designer to identify which parameter changes will reduce stress and give the desired displaced shape. These equations and parameters were coded into ANSYS batch files that were used to run the analyses.

A parametric CAD model was also created in SolidWorks that takes the same inputs as the ANSYS parametric model. It creates a 3D model with the same geometry that the ANSYS model represents by accounting for thicknesses of beams. This allowed for time-efficient modeling and prototyping of designs. Figure 1 shows a CAD model that was created using the parametric CAD model.

The model was verified with prototypes constructed in three different materials, as described later.

\section{Configuration Study}

The parametric finite element model was used to conduct a configuration study to explore and analyze different combinations of parameters. Figure 
6 shows the different geometric variations that were analyzed. Visual depictions of several of the configurations are shown with their descriptions in this section. The configuration study provided a better understanding of how each of the parameters affects the stress and displaced shape and decreased the design time required for prototypes on different size scales or of different materials.

\subsection{Radial Configurations}

To begin the exploration of different configurations, consider the design where each of the flexures pointed directly to the center of rotation, similar to radial serpentine flexures [17]. The loading would benefit from a transmission angle closest to $90^{\circ}$, making the load perpendicular to the flexure and the flexure obtaining maximum deflection from the load. Designs were explored and analyzed that changed the angles of Figure 5(a) and length factors of Figure 5(b) to make three out of the four flexures per quadrant point to the center and then another to have all the flexures point to the center. These designs are depicted in the line drawings of Figure 7. Four additional keypoints, 42, 43, 44, and 45, were added to accommodate the fully radial design of Figure 7(b) and are only needed for fully radial designs.

The addition of keypoints to obtain a fully radial design increased the arc length of the two inner intermediate blocks and created self-interference issues. The fully radial design was unable to achieve $90^{\circ}$ of rotation for the specified properties and limitations. The design with three radial flexures achieved $90^{\circ}$ but predicted higher stresses than the horizontal configuration, shown in Figure 8. Having the centerline between the second and third flexure per quadrant pass through the center of rotation showed a decrease in stress and was adopted into future design configurations.

\subsection{Flexure Length Configurations}

The differences between designs with different relative lengths were compared, including where

1. the four flexures per quadrant are all different length

2. the first and second flexures per quadrant are the same length and the third and fourth flexures per quadrant are the same length

3. all four flexures per quadrant are the same length

The second and third concepts were tested against the first and are shown in line drawings in Figure 9. 


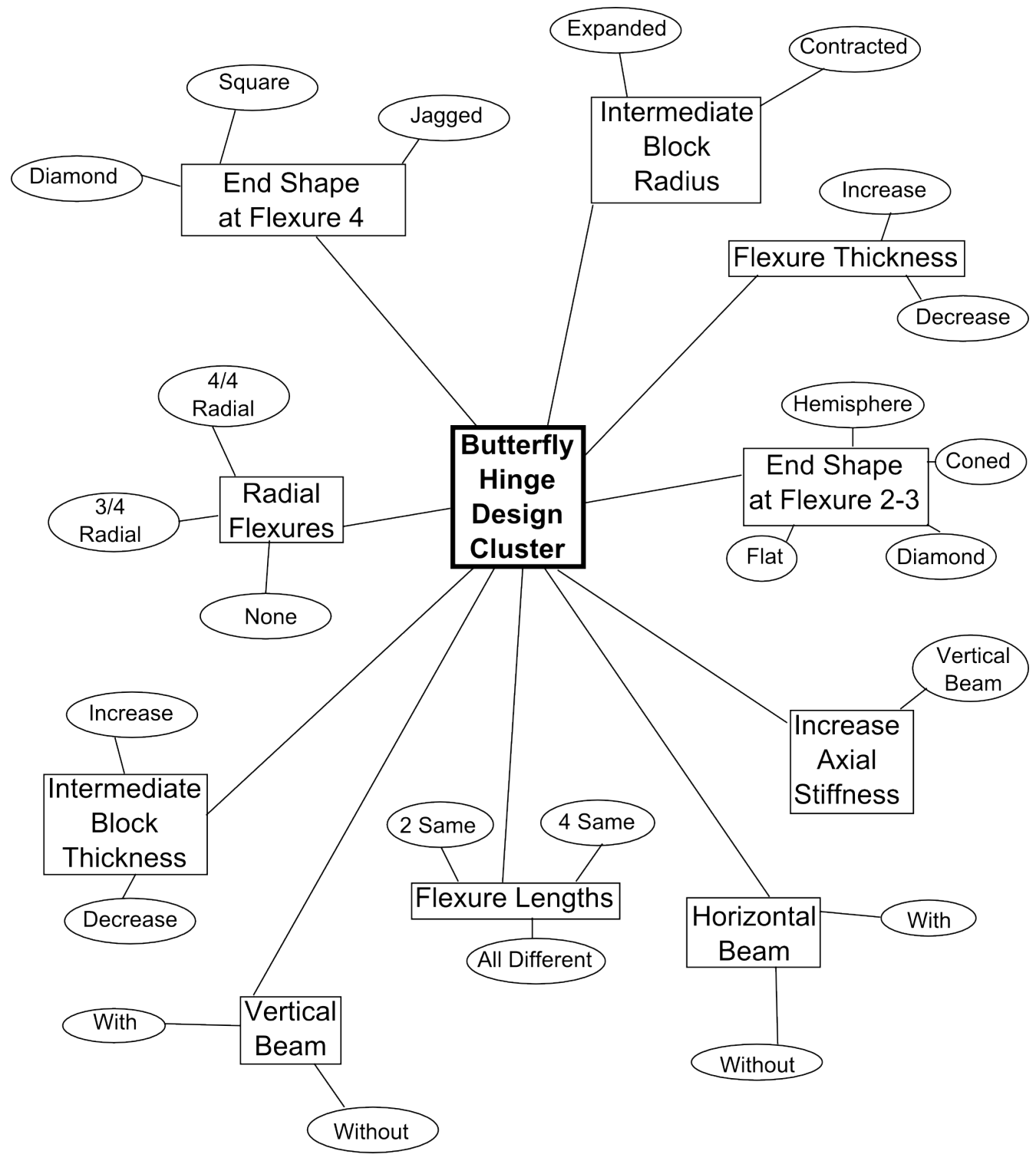

Figure 6: Design configuration cluster. 


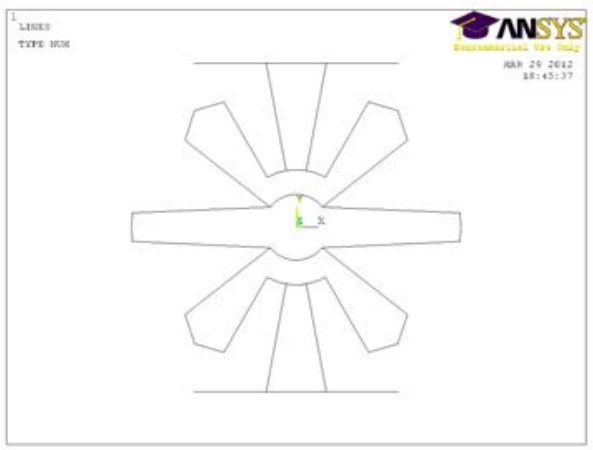

(a) 3 out of 4 flexures are radial

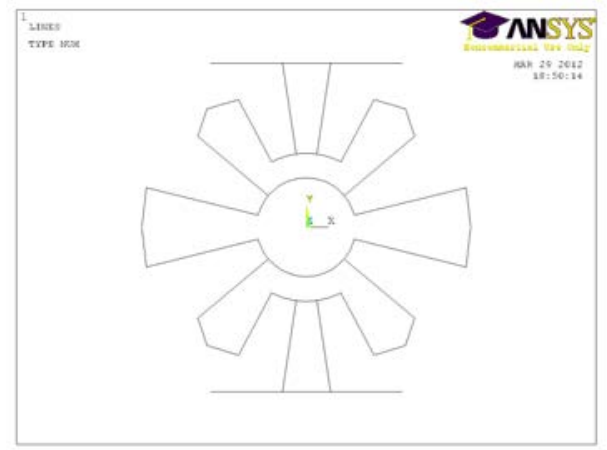

(b) 4 out of 4 flexures are radial

Figure 7: Radial configurations.

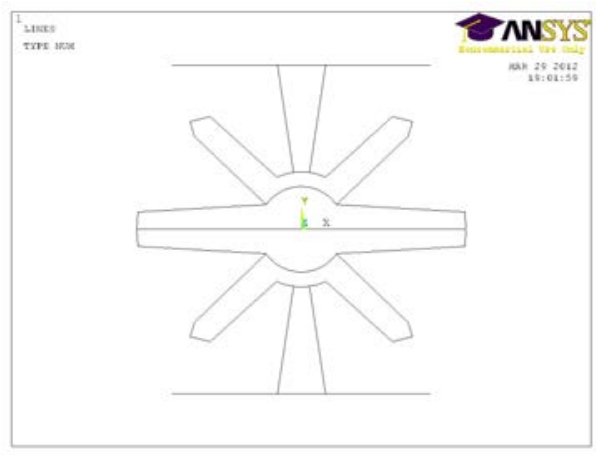

Figure 8: Horizontal configuration. 


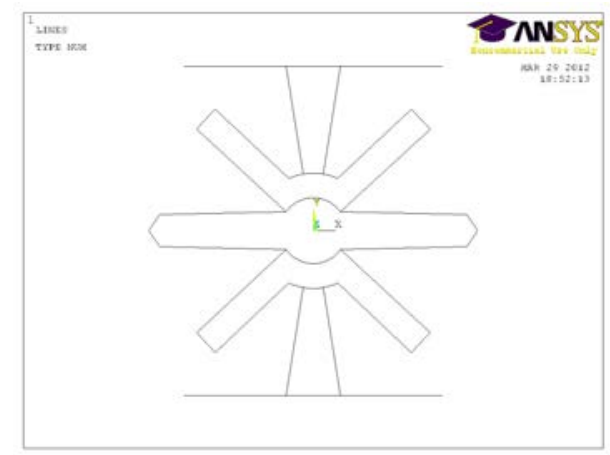

(a) 2 pairs of flexures are each the same length

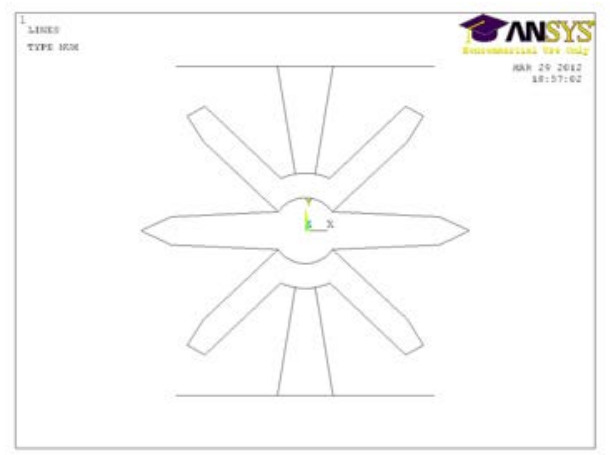

(b) 4 out of 4 flexures are the same length

Figure 9: Flexure length configurations.

In the cases evaluated, the longer the flexure length, the lower the stress in that flexure. It is advantageous to make every flexure as long as possible and still have them all fit within the hinge and not interfere with each other.

\subsection{End Shape Configurations}

The end shape refers to the geometry of the segments that connect the outer ends of the flexures. These segments are flexures as well but don't experience large deflection are were investigated to see how they affect the deflection of the 16 flexures. After investigating squared, diamond, hemispherical and other end cap shapes, the results suggested that it would be advantageous to maximize the length of each flexure and that the end shapes reduced the effective flexure length and increased stresses. Figure 10 shows a line drawing of the hemispherical configuration.

To maximize the length of each flexure and still avoid self-interference, the length factors and angles were adjusted until the flexures were as long as possible while the predicted displaced shape did not self-intersect. This design resulted in a lower maximum stress, going from above $24 \mathrm{MPa}$ to just below $17 \mathrm{MPa}$.

\subsection{Vertical Configuration}

The designs without a flexure in the center had poor axial stiffness. To address this problem, a vertical flexure was added between the inner inter-

mediate blocks, as shown in Figure 11. Two additional keypoints, 46 and 


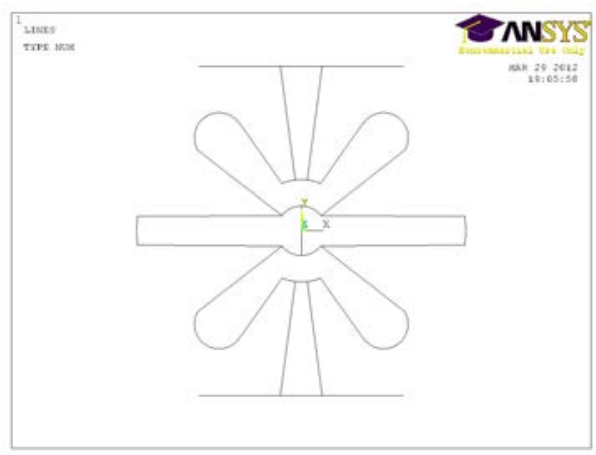

Figure 10: Hemisphere configuration.

47, were added to accommodate a vertical flexure design. The design with the addition of the vertical flexure did not self-intersect, had a much lower maximum stress, and deflected $90^{\circ}$.

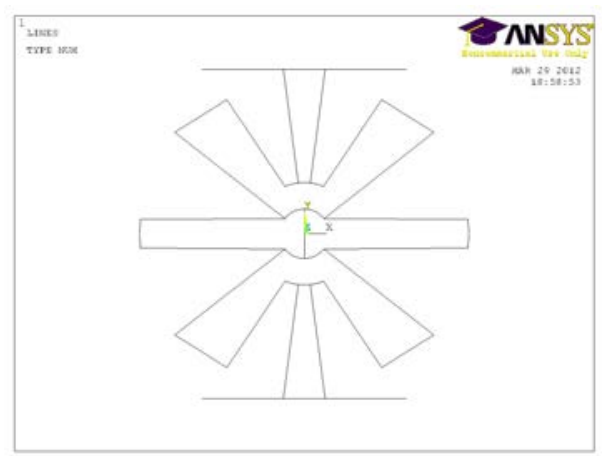

Figure 11: Vertical configuration.

The vertical flexure proved effective in increasing the axial stiffness of the design while allowing for the desired displacement and a similar displaced shape. The addition of a vertical flexure helped to improve distribution of the stress and slightly lowered the maximum stress.

\subsection{Flexure Thickness}

The in-plane thickness of the flexures, $t 1$, is independent of the other design variables and can be used to lower or raise stresses. The lower limit is a function of manufacturing feasibility. During design, the thickness of 
the flexures was decreased to reduce stress, but this also results in reduced stiffness. The stiffness must also match the applied torque across the hingeline defined by the design requirements. If the hinge is not stiff enough, it would be necessary to use several of them in parallel and the cost and production time would increase. Increasing flexure thickness also provides increased off-axis stiffness and increases the stability of the hinge.

\subsection{Intermediate Block Placement and Thickness}

The intermediate blocks provide stability for the hinge by helping to guide the 16 flexures through the range of motion. The in-plane thickness of the intermediate blocks, $t 2$, has a large effect on self-interference problems. If made too thick, they will come into undesirable contact during deflection. Friction in contact surfaces is a possible failure mode for the hinge in space applications and must be avoided. If the intermediate blocks are too thin, they become flexures and cease to provide stability and symmetry to the hinge.

The distance of the two pairs of intermediate blocks from the center are defined by length factors $f 2$ and $f 7$. For the conditions evaluated, if the radii were increased, the length of the flexures was decreased and the stresses increased. It was also found that if the radii were decreased past a certain value, the location of the maximum stress would change, the maximum stress would increase, and self-interference would also occur. Two length factor values were chosen that balanced these competing outcomes.

\subsection{Overall Size of the Hinge}

The radius of the overall hinge, $R$, determines the size of the hinge since every keypoint parametrically scales according to it. This parameter allows the designer to design the hinge on any scale. When the radius is decreased, the length of the flexures decrease and the stress increases. When sizing down, the flexure thickness needs to be decreased to keep within stress limits. The design is bounded by stress as the size decreases since there are physical boundaries, related to manufacturing processes, on how thin the flexures can be.

\subsection{Summary of Lessons Learned from the Configuration Study}

Different configurations were combined and the Flex-16 was a composite of the best qualities of each of the different branches of the cluster. The design configuration found by exploring and analyzing these different configurations 
maximizes the hinge capability and results in the lowest stress for any size of the hinge. This means that when scaling up or down, without changing materials, the only parameter necessary to adjust is the flexure thickness. Some of the resulting design characteristics are

- the first and third flexure of each quadrant are radial

- the end shape is squared (with fillets to reduce stress concentrations)

- none of the flexures are the same length

- the length of each flexure is maximized without self-interference

- the horizontal beam was removed and a vertical flexure was added

- the intermediate blocks were positioned at an optimal radii

- the intermediate block thickness is adequate for stability and avoids self-interference

- the flexure thickness was set to reduce stress and still be manufacturable

If the material used for the hinge changes, the designer needs only to change the material properties in the parametric ANSYS model. When the material and scale changes, adjustment of all the parameters is required.

\section{Results}

\subsection{Overview of Prototypes}

After the configuration study was completed, and the Flex-16 characteristics determined, five prototypes were fabricated using three different materials and three different manufacturing processes. Table 2 describes the five prototypes.

Prototypes were fabricated at the micro and macro size scales. Table 3 lists the parameters that describe the design for each of the five prototypes.

In the upper section of the table, the radius ( $\mathrm{R})$, flexure thickness (t1), the intermediate shuttle thickness (t2), and the out-of-plane hinge width (w) for each of the prototypes are listed. This can be used for a quick comparison of the sizes of the prototypes. In the middle section of the table, the 8 angles (a1-a8) used to define the 47 keypoints are listed for each prototype. In the lower section of the table, the 8 length factors (f1-f8) used to define the 47 keypoints are listed for each prototype. The middle and lower sections can be used for a quick comparison of the designs of the prototypes. 
Table 2: Prototype materials and processes

\begin{tabular}{|cll|}
\hline & & \\
Name & Material & Manufacturing Process \\
\hline PP-1 & Polypropylene & CNC Milling \\
PP-2 & Polypropylene & CNC Milling \\
Ti-1 & Titanium Ti6Al4V & Electron Beam Rapid Prototyping \\
CNT-1 & Carbon Nanotubes & CNT Framework Growth \& Infiltration \\
CNT-2 & Carbon Nanotubes & CNT Framework Growth \& Infiltration \\
\hline
\end{tabular}

Table 3: Prototype design parameters

\begin{tabular}{|clllll|}
\hline & & & & & \\
Parameter & PP-1 & PP-2 & Ti-1 & CNT-1 & CNT-2 \\
\hline $\mathrm{R}$ & $15.24 \mathrm{~cm}$ & $15.24 \mathrm{~cm}$ & $6.66 \mathrm{~cm}$ & $4 \mathrm{~mm}$ & $2 \mathrm{~mm}$ \\
$\mathrm{t} 1$ & $2.5 \mathrm{~mm}$ & $2.5 \mathrm{~mm}$ & $0.7 \mathrm{~mm}$ & $30 \mu \mathrm{m}$ & $20 \mu \mathrm{m}$ \\
$\mathrm{t} 2$ & $8.0 \mathrm{~mm}$ & $8.0 \mathrm{~mm}$ & $3.0 \mathrm{~mm}$ & $100 \mu \mathrm{m}$ & $80 \mu \mathrm{m}$ \\
$\mathrm{w}$ & $1.27 \mathrm{~cm}$ & $1.27 \mathrm{~cm}$ & $1.27 \mathrm{~cm}$ & $250 \mu \mathrm{m}$ & $250 \mu \mathrm{m}$ \\
\hline $\mathrm{al}$ & $10^{\circ}$ & $7^{\circ}$ & $7^{\circ}$ & $10^{\circ}$ & $10^{\circ}$ \\
$\mathrm{a} 2$ & $25^{\circ}$ & $22^{\circ}$ & $22^{\circ}$ & $25^{\circ}$ & $25^{\circ}$ \\
$\mathrm{a} 3$ & $39^{\circ}$ & $30^{\circ}$ & $34^{\circ}$ & $39^{\circ}$ & $39^{\circ}$ \\
$\mathrm{a} 4$ & $46^{\circ}$ & $41^{\circ}$ & $45^{\circ}$ & $46^{\circ}$ & $46^{\circ}$ \\
$\mathrm{a} 5$ & $49^{\circ}$ & $52^{\circ}$ & $56^{\circ}$ & $49^{\circ}$ & $49^{\circ}$ \\
$\mathrm{a} 6$ & $55^{\circ}$ & $52^{\circ}$ & $57^{\circ}$ & $55^{\circ}$ & $55^{\circ}$ \\
$\mathrm{a} 7$ & $84^{\circ}$ & $85^{\circ}$ & $85^{\circ}$ & $84^{\circ}$ & $84^{\circ}$ \\
$\mathrm{a} 8$ & $90^{\circ}$ & $90^{\circ}$ & $90^{\circ}$ & $90^{\circ}$ & $90^{\circ}$ \\
\hline $\mathrm{fl}$ & 1.05 & 1.05 & 1.05 & 1.05 & 1.05 \\
$\mathrm{f} 2$ & 0.35 & 0.31 & 0.29 & 0.35 & 0.35 \\
$\mathrm{f} 3$ & 0.88 & 0.94 & 0.94 & 0.88 & 0.88 \\
$\mathrm{f} 4$ & 1.25 & 1.25 & 1.25 & 1.25 & 1.25 \\
$\mathrm{f} 5$ & 0.94 & 0.95 & 0.95 & 0.94 & 0.94 \\
$\mathrm{f} 6$ & 0.86 & 1.0 & 1.0 & 0.86 & 0.86 \\
$\mathrm{f} 7$ & 0.20 & 0.15 & 0.15 & 0.20 & 0.20 \\
$\mathrm{f} 8$ & 0.90 & 1.0 & 1.0 & 1.0 & 1.0 \\
\hline
\end{tabular}




\subsection{Overview and Summary of Analyses Performed on Prototypes}

The parametric finite element model in ANSYS was used to calculate the following for each prototype:

- Displaced Shape

- Stiffness

- Stresses

A stiffness plot and a stress/displaced shape plot were created for each of the five prototypes. The two plots are shown for one prototype, PP-2; the plots for the other prototypes are similar but with different magnitudes. The maximum von Mises stress (at 90 $)$ and rotational stiffness results for the five prototypes are summarized in Table 4.

Table 4: Prototype predicted stress and stiffness from ANSYS

\begin{tabular}{|llll|}
\hline Name & $\begin{array}{l}\text { Maximum } \\
\text { Stress at } 90^{\circ}\end{array}$ & $\begin{array}{l}\text { Yield Factor } \\
\text { of Safety }\end{array}$ & Rotational Stiffness \\
\hline PP-1 & $20.6 \mathrm{MPa}$ & 1.50 & $0.4497 \mathrm{~N}-\mathrm{m} / \mathrm{rad}$ \\
PP-2 & $15.3 \mathrm{MPa}$ & 2.02 & $0.3113 \mathrm{~N}-\mathrm{m} / \mathrm{rad}$ \\
Ti-1 & $805 \mathrm{MPa}$ & 1.03 & $1.2719 \mathrm{~N}-\mathrm{m} / \mathrm{rad}$ \\
CNT-1 & $30.0 \mathrm{MPa}$ & 3.50 & $1.7405 \mathrm{~N}-\mathrm{m} / \mathrm{rad}$ \\
CNT-2 & $40.1 \mathrm{MPa}$ & 2.62 & $1.0327 \mathrm{~N}-\mathrm{m} / \mathrm{rad}$ \\
\hline
\end{tabular}

The ANSYS predicted stiffness plot for PP-2 is shown in Figure 12. The predicted stiffness is nearly linear. The ANSYS predicted stress and displaced shape plot for PP-2 is shown in Figure 13. The maximum von Mises stress is predicted to be $15.3 \mathrm{MPa}$ and is located at the junction of the flexures and the intermediate rigid shuttles.

Table 5 lists the material properties used for the analysis of the prototypes. The tensile yield strengths for polypropylene and titanium are on the low end of the commonly given ranges; adding conservatism to the designs. If a Young's Modulus of $41 \mathrm{MPa}$ (higher end of the range) is used instead, the predicted rotational stiffness is $0.5057 \mathrm{~N}-\mathrm{m} / \mathrm{rad}$ and $0.03502 \mathrm{~N}-\mathrm{m} / \mathrm{rad}$ for PP-1 and PP-2, respectively. The tensile yield strength and Young's modulus for the carbon nanotube framework are estimated values as this is an active area of research and the properties are still being verified by testing. 


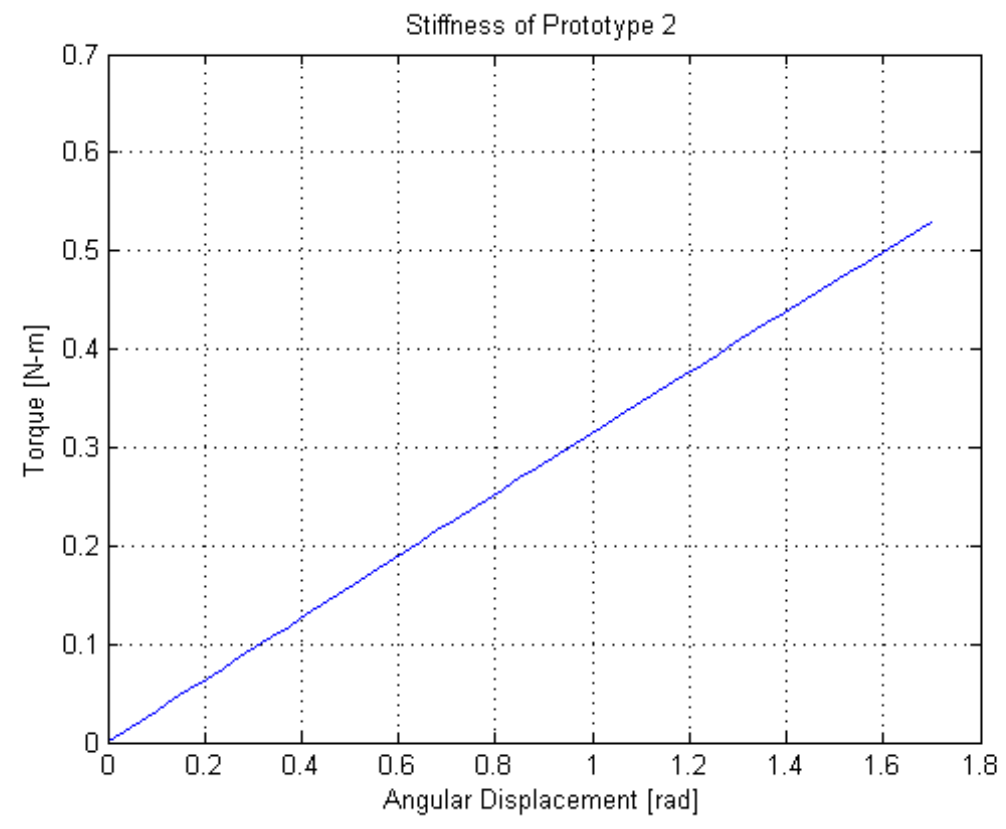

Figure 12: Predicted stiffness of PP-2.

When further material properties data is available for in-plane loading conditions, the material properties will provide a more accurate prediction of the displaced shape and stress.

Table 5: Prototype material properties

\begin{tabular}{|lllll|}
\hline Material & $\begin{array}{l}\text { Tensile Yield } \\
\text { Strength }\end{array}$ & $\begin{array}{l}\text { Young's } \\
\text { Modulus }\end{array}$ & $\begin{array}{l}\text { Poisson's } \\
\text { Ratio }\end{array}$ & Density \\
\hline Polypropylene & $31 \mathrm{MPa}$ & $1.379 \mathrm{GPa}$ & 0.3 & $900 \mathrm{~kg} / \mathrm{m}^{3}$ \\
Titanium & $827 \mathrm{MPa}$ & $113.8 \mathrm{GPa}$ & 0.34 & $2360 \mathrm{~kg} / \mathrm{m}^{3}$ \\
Carbon Nanotubes & $105 \mathrm{MPa}$ & $6 \mathrm{GPa}$ & 0.28 & - \\
\hline
\end{tabular}

The following additional analyses were performed on specified prototypes and are shown in later sections:

- Parasitic Center Shift

- Modal Analysis 


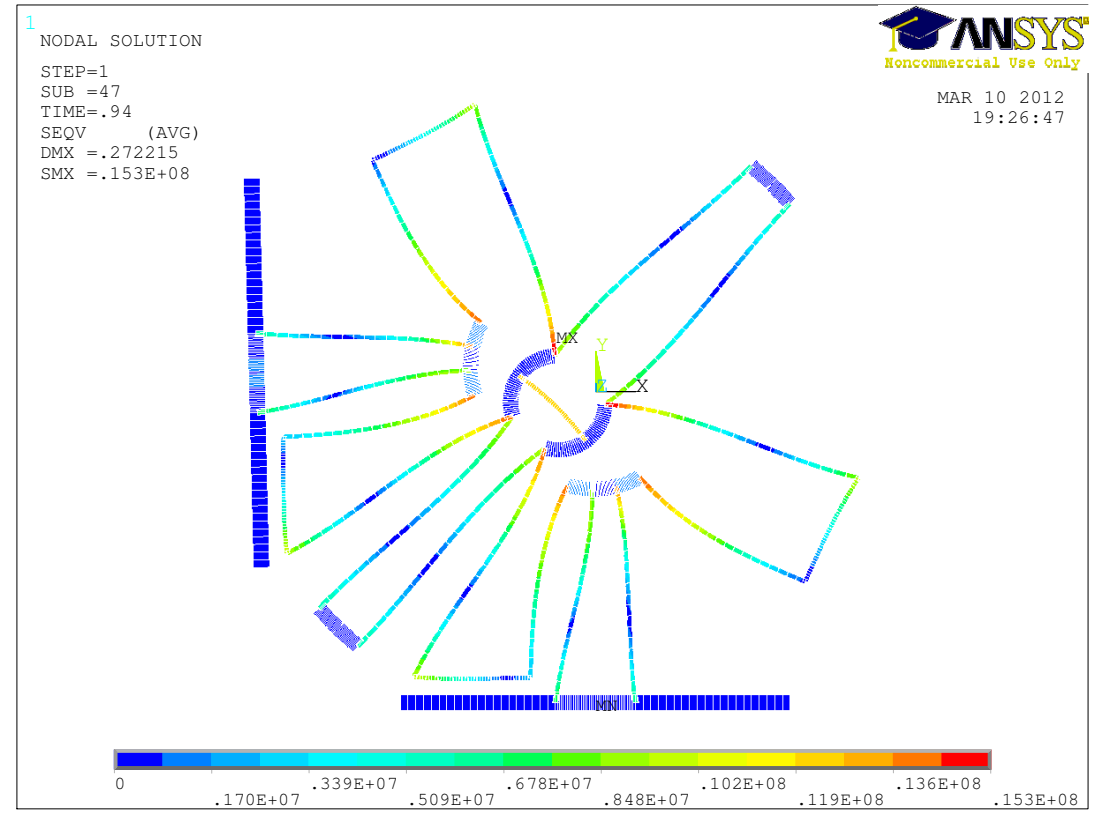

Figure 13: Predicted stress of PP-2. Maximum stress is located in the flexures where they meet the intermediate shuttles. 
- Thermal Stresses

- Off-Axis Stiffness

\section{Polypropylene Prototypes PP-1 \& PP-2}

\subsection{Model Verification}

Two polypropylene prototypes were created to test the performance of the Flex-16 design and validate the analytical model. They were fabricated on a CNC mill and are shown in Figures 14(a) and 14(b).

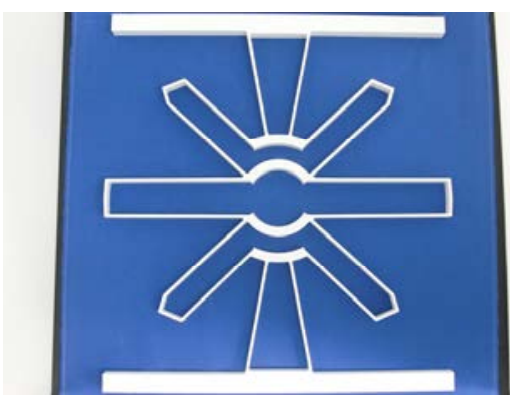

(a) PP-1

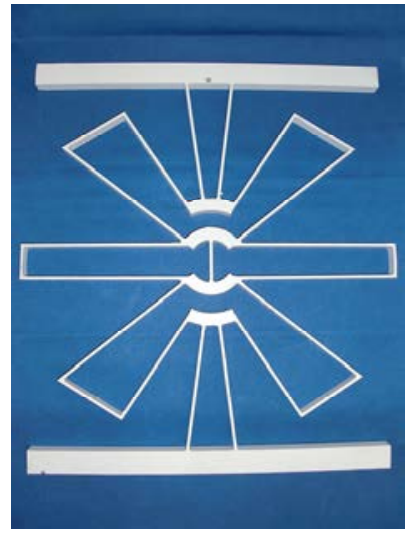

(b) PP-2

Figure 14: Two Flex-16 prototypes fabricated from polypropylene.

PP-1 was deflected from $0^{\circ}$ to $90^{\circ}$ and Figure 15 shows the prototype at $0^{\circ}, 45^{\circ}$, and $90^{\circ}$. The same is shown for PP-2 in Figure 16.

Both polypropylene prototypes were able to rotate $90^{\circ}$ without failure, as predicted by the analytical model. PP-1 showed contact of the horizontal flexures at $90^{\circ}$. PP-2 demonstrated a more desirable displaced shape with only minimal contact with the fixed base.

The force required to hold the prototype in a position where it was deflected to $90^{\circ}$ was measured and compared to the analytical prediction from ANSYS. The comparison is shown in Table 6 . The correlation factor describes the degree to which ANSYS is under-predicting the force required to hold deflected at $90^{\circ}$. The differences in the values originate primarily from the variability of the material properties of polypropylene. The Young's 


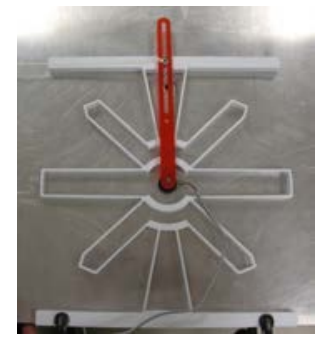

(a) PP-1 at $0^{\circ}$

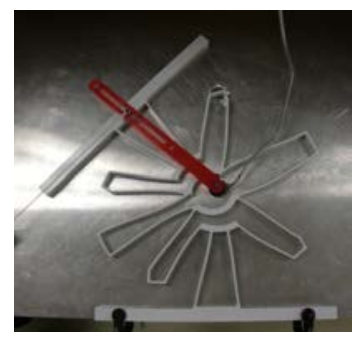

(b) $\mathrm{PP}-1$ at $45^{\circ}$

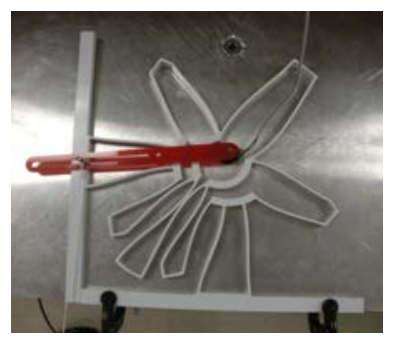

(c) PP-1 at $90^{\circ}$

Figure 15: PP-1 deflected from $0^{\circ}$ to $45^{\circ}$ and $90^{\circ}$.

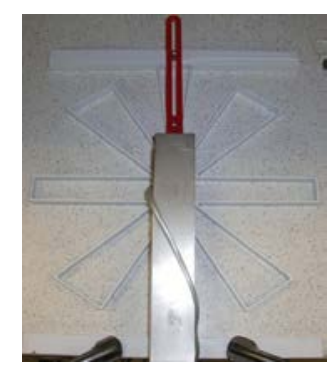

(a) PP-2 at $0^{\circ}$

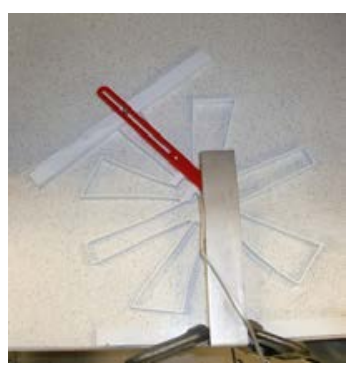

(b) PP-2 at $45^{\circ}$

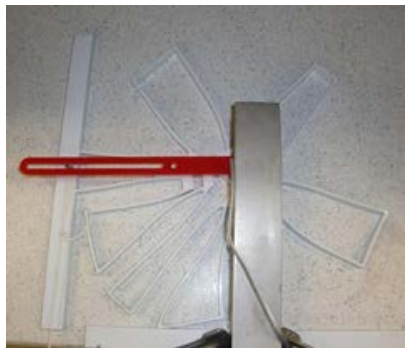

(c) PP-2 at $90^{\circ}$

Figure 16: PP-2 deflected from $0^{\circ}$ to $45^{\circ}$ and $90^{\circ}$.

Modulus used for the analysis was at the low end of the range of common values which adds conservatism to the design but increases the error in the predicted stiffness.

\subsection{Parasitic Center Shift}

The center of the hinge shifts during rotation and can be a challenge if used in precision applications. The maximum parasitic center shift occurs when the hinge is deflected to the point where the rigid shuttles come into contact. The measured parasitic center shift at $90^{\circ}$ for PP-2 is listed in Table 7 .

To put the center shift in context of the size of the hinge, the $\mathrm{x}$-direction shift is 0.129 times the radius and the y-direction shift is 0.046 times the radius. The rotation of the center point is approximately $45^{\circ}$ as expected.

The motion of the center point between the two indicated locations in Figure 17 can be seen in Figure 18. 
Table 6: Model validation - comparison of $\mathrm{Y}$ direction force required to hold deflection at $90^{\circ}$

\begin{tabular}{|llll|}
\hline Prototype & $\begin{array}{l}\text { Predicted } \\
\text { Y Force }\end{array}$ & $\begin{array}{l}\text { Tested } \\
\text { Y Force }\end{array}$ & $\begin{array}{l}\text { Correlation } \\
\text { Factor }\end{array}$ \\
\hline PP-1 & $5.12 \mathrm{~N}$ & $6.76 \mathrm{~N}$ & 1.32 \\
PP-2 & $3.42 \mathrm{~N}$ & $4.89 \mathrm{~N}$ & 1.43 \\
\hline
\end{tabular}

Table 7: Magnitude of parasitic center shift for PP-2 at $90^{\circ}$

\begin{tabular}{|ccc|}
\hline X Displacement & Y Displacement & Rotation in Z \\
\hline$-19.7 \mathrm{~mm}$ & $-7.0 \mathrm{~mm}$ & $0.798 \mathrm{rad}$ \\
\hline
\end{tabular}

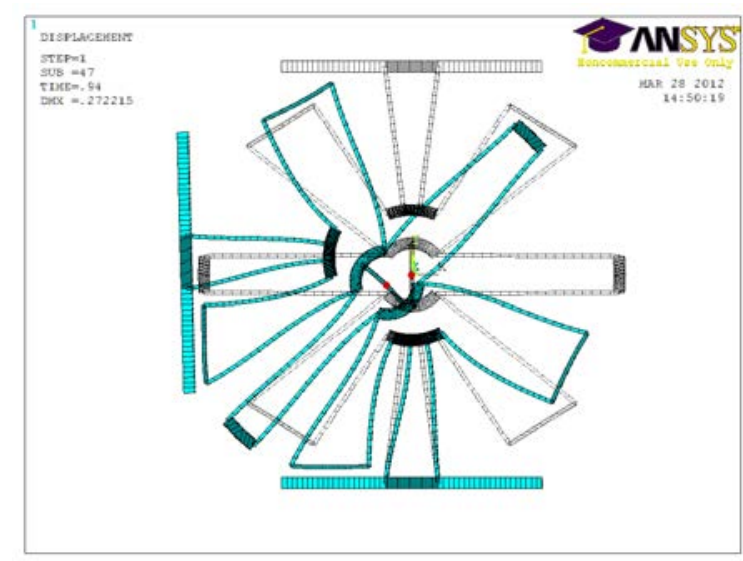

Figure 17: Visual depiction of center shift.

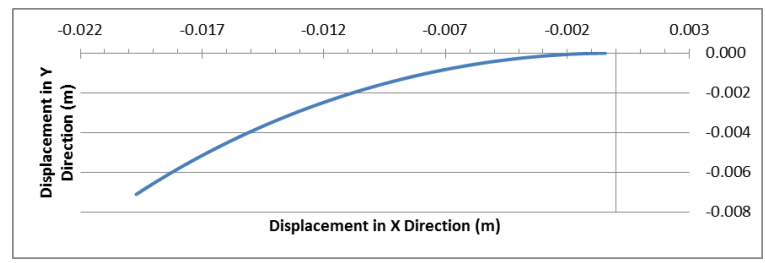

Figure 18: Motion of center shift predicted for PP-2. 
The center shift on a compliant deployment hinge is a problem if it is not quanitified properly. If it is quanitified and taken into account, it can be part of the predictable behavior of the system.

\subsection{Additional Testing}

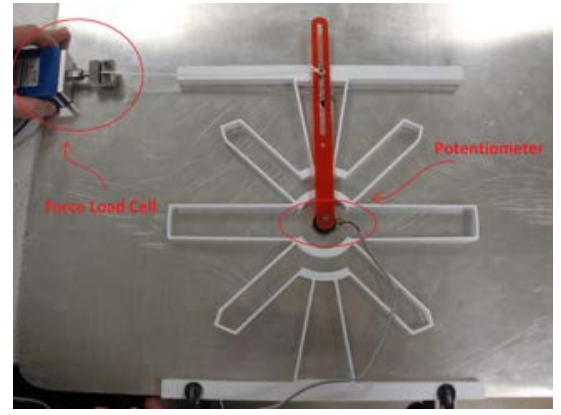

(a) PP-1 test setup

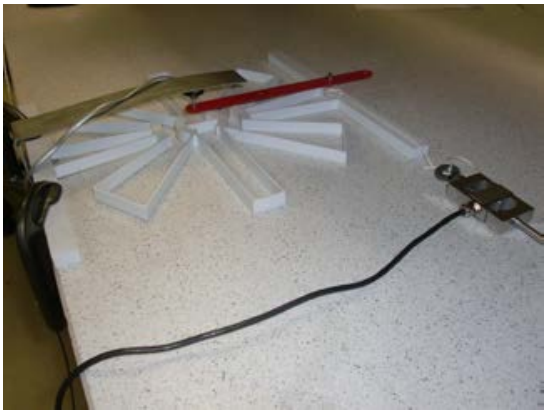

(b) PP-2 test setup

Figure 19: Test setup for PP-1 and PP-2.

PP-1 and PP-2 were deflected to $90^{\circ}$ then undeflected, to experimentally measure the rotational stiffness. The testing was performed using a force load cell, a potentiometer, and a LabView program calibrated to output and plot the force-displacement data, as shown in Figure 19 for both prototypes.

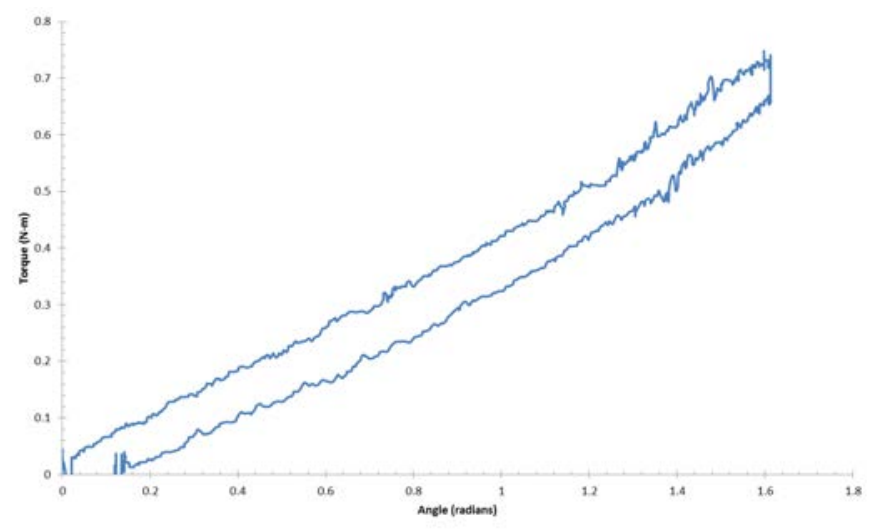

Figure 20: Deflection test results for PP-2.

A load cell measured force normal to the moment arm, at a distance specified by the radius $(\mathrm{R})$ of the design, while a calibrated potentiometer 
measured rotational displacement. The data from the load cell and potentiometer were brought into LabView. The force data from LabView was multiplied by the moment arm and plotted against the rotation data. The data for PP-2 is plotted in Figure 20 and the data for PP-1 followed similar trends and is available upon request.

Using polypropylene leads to the hysteresis that can be seen in the plots as the difference in the deflecting and undeflecting stiffnesses. Table 8 re-

Table 8: PP-1 \& PP-2 tested rotational stiffness

\begin{tabular}{|lll|}
\hline & & \\
Prototype & Tested Stiffness & $\mathrm{R}^{2}$ \\
\hline PP-1 & $0.5841 \mathrm{~N}-\mathrm{m} / \mathrm{rad}$ & 0.9981 \\
PP-2 & $0.4376 \mathrm{~N}-\mathrm{m} / \mathrm{rad}$ & 0.9959 \\
\hline
\end{tabular}

ports the tested rotational stiffness of PP-1 and PP-2 along with the linear approximation correlation coefficient. The tested stiffnesses are nearly linear.

\section{Titanium Prototype Ti-1}

A titanium hinge was designed, analyzed, and fabricated. It was prototyped at NASA Marshall Space Flight Center using an electron beam manufacturing metal rapid prototyping process [23]. Ti-1 is shown in its undeflected state in Figure 21.

The predicted displaced shape and stress plot is shown in Figure 22(b) for comparison with the deflected prototype in Figure 22(a).

There is no self-interference or contact during deflection and it achieves $90^{\circ}$ of rotational displacement without failure. The prototype deflected shape is predicted by the finite element model.

\subsection{Modal Analysis}

Modal analysis was performed for PP-2 and Ti-1 designs using ANSYS. The first 10 mode shapes and natural frequencies were found and the first two mode shapes are shown in Figures 23(a) and 23(b). Table 9 lists the first five natural frequencies for both prototypes. The first natural frequency excites a simple rotational mode shape. The second natural frequency excites a simple axial (up and down) mode shape. The third and higher natural frequencies are complex mode shapes. The first natural frequency for Ti-1 is high enough to avoid most low frequency launch vibrations for space applications. 


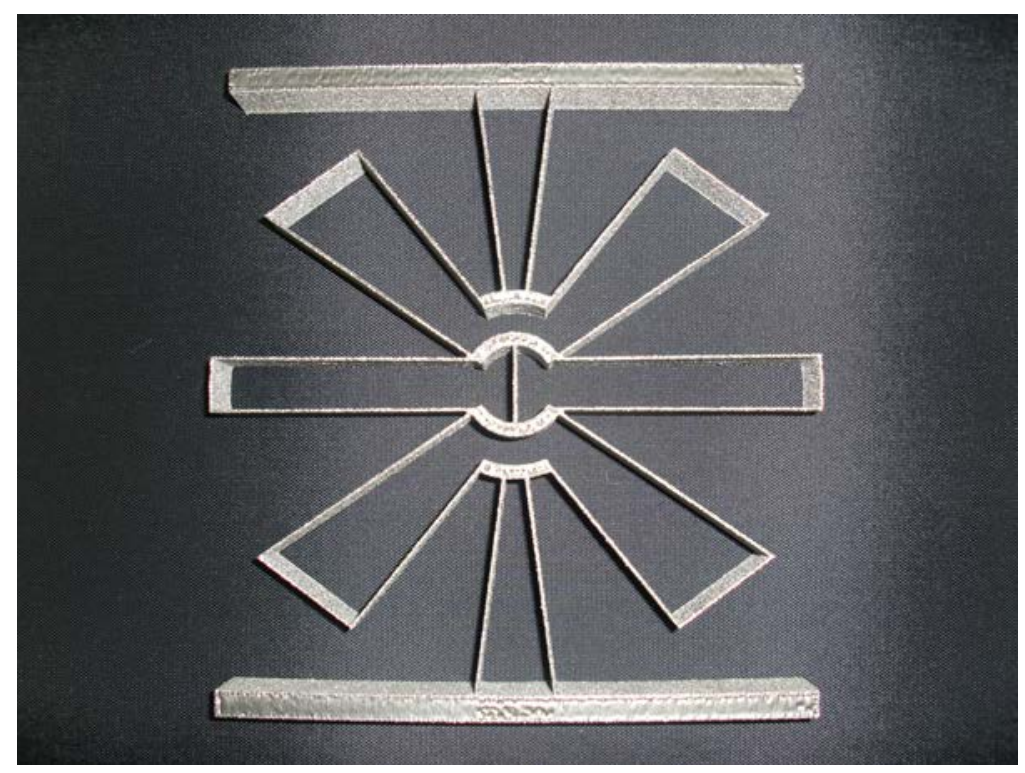

Figure 21: Prototype Ti-1 as fabricated at NASA Marshall Space Flight Center.

Table 9: Prototype natural frequencies in $\mathrm{Hz}$

\begin{tabular}{|llllll|}
\hline & & & & \\
Natural Frequency & 1 & 2 & 3 & 4 & 5 \\
\hline PP-2 & 2.99 & 8.47 & 11.76 & 12.92 & 19.26 \\
Ti-1 & 21.51 & 58.73 & 86.99 & 96.79 & 137.63 \\
\hline
\end{tabular}




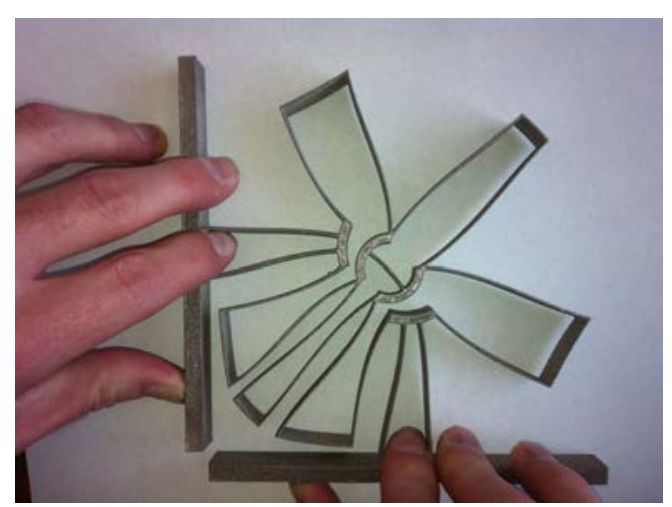

(a) Ti-1 deflected to $90^{\circ}$.

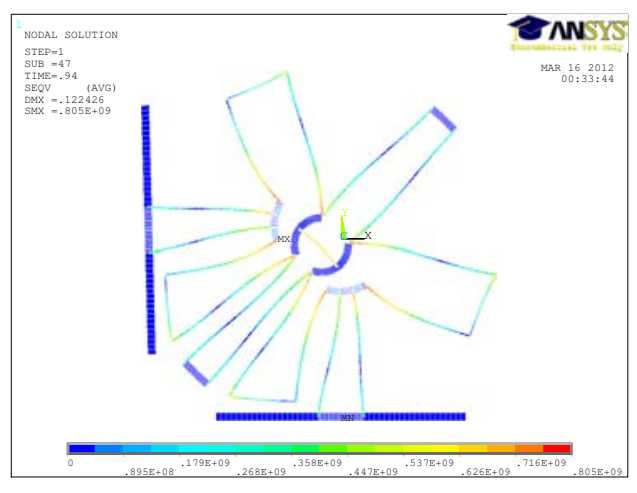

(b) Ti-1 predicted deflection and stress from ANSYS.

Figure 22: Tested and predicted displaced shape for prototype Ti-1.

\subsection{Thermal Stresses}

A thermal analysis was performed in ANSYS for prototype Ti-1 to simulate typical space environment temperatures. It was analyzed for both -35 ${ }^{\circ} \mathrm{C}$ and $75^{\circ} \mathrm{C}$, using a reference temperature of $20^{\circ} \mathrm{C}$. A thermal expansion coefficient of $8.6 * 10^{-6} \mathrm{~m} / \mathrm{mK}$ was used in the analysis. The thermal stress plot is shown in Figure 24 with a predicted maximum von Mises stress due to thermal expansion/contraction of 1.6 MPa. The location of maximum stress is at the end of the third flexure per quadrant and is different from the location of maximum stress from rotational displacement. The thermal stresses are low but could be added as a preload to the displacement model.

\subsection{Off-Axis Stiffness}

The off-axis stiffness in the axial direction of prototype Ti-1 was found to be $3107.4 \mathrm{~N} / \mathrm{m}$. This means it would require $37.28 \mathrm{~N}$ of vertical force to deflect the hinge vertically $12 \mathrm{~mm}$ until the rigid intermediate shuttles contact. The displaced shape and stresses at this point are shown in Figure 25. The maximum von Mises stress is predicted to be $327 \mathrm{MPa}$ and is at the same location as for thermal stresses. With the maximum stress from axial loading being nearly 40 percent of yield, it is important to avoid axial forces when rotating the hinge to very large displacements. The vertical flexure 


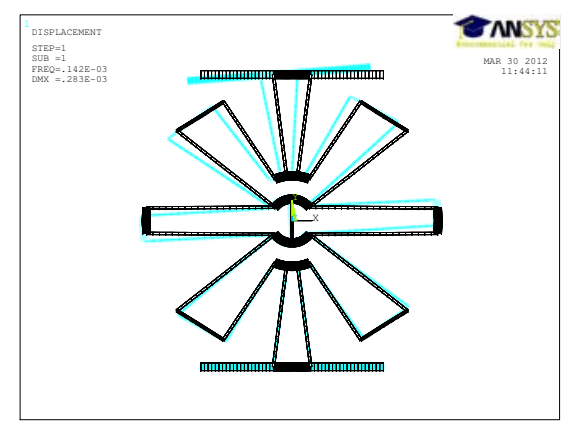

(a) First mode shape

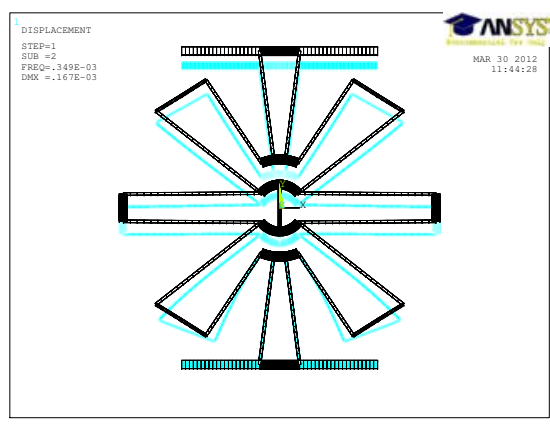

(b) Second mode shape

Figure 23: Flex-16 mode shapes 1 and 2 from ANSYS modal analysis.

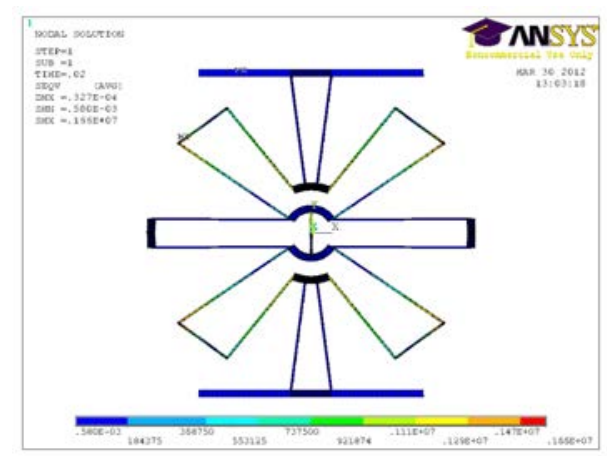

Figure 24: Plot of thermal stresses for Ti-1 at 75 and $-35{ }^{\circ} \mathrm{C}$.

increases off-axis axial stiffness, but it could be further increased to alleviate concerns with launch vibrations.

\subsection{Additional Testing}

Ti-1 was tested to experimentally measure the rotational stiffness. The force data from LabView was multiplied by the moment arm and plotted against the rotation data. The data for Ti-1 is plotted in Figure 26.

Table 10 reports the tested rotational stiffness of $\mathrm{Ti}-1$ along with the linear approximation correlation coefficient. 


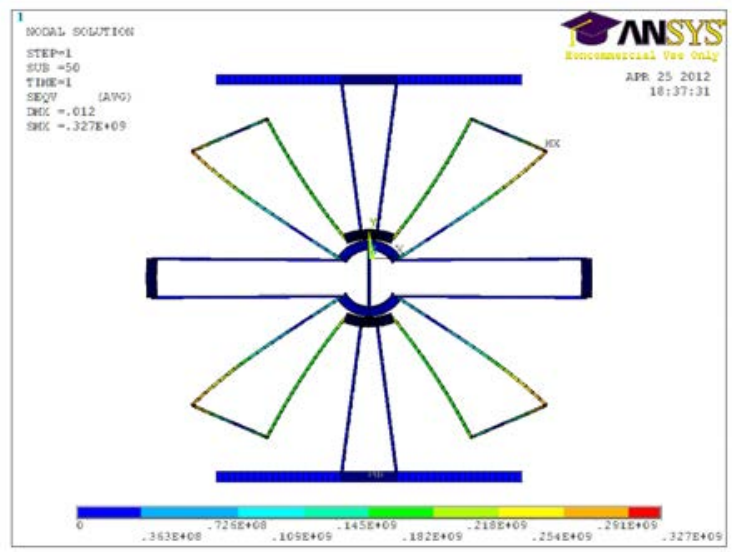

Figure 25: Displaced shape and stress from off-axis loading of Ti-1.

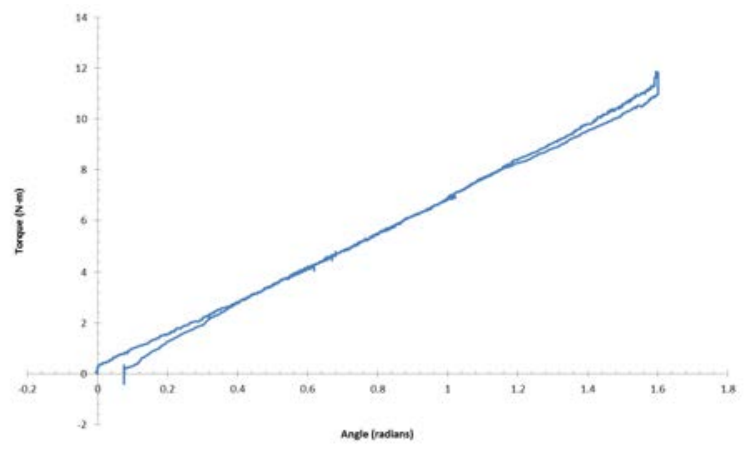

Figure 26: Ti-1 tested rotational stiffness.

Table 10: Ti-1 tested rotational stiffness

\begin{tabular}{|lll|}
\hline & & \\
Prototype & Tested Stiffness & $\mathrm{R}^{2}$ \\
\hline Ti-1 & $0.7885 \mathrm{~N}-\mathrm{m} / \mathrm{rad}$ & 0.9974 \\
\hline
\end{tabular}




\section{Carbon Nanotube-Framework Prototypes CNT-1 \& CNT-2}

Two designs were created for micro-scale applications and were fabricated from a carbon nanotubes framework process [24]. This served as a preliminary investigation of the feasibility of rotational joints on the micro scale as well as aiding in gathering more data to refine our understanding of the material properties of carbon nanotubes undergoing in-plane loading. It also served to demonstrate the scalability of the Flex-16 hinge.

The carbon nanotubes framework process used is summarized as follows. Both designs (CNT-1 \& CNT-2) were modeled in CAD software. 2D outlines were created from the geometry in another program where the profile of the designs were augmented with drawings of necessary support structures. The finished drawings were used to make the mask for performing photolithography. The mask is used to generate the pattern in the photoresist on an alumina coated silicon wafer. The exposed photoresist is chemically dissolved. A thin layer of iron is deposited on the wafer. Another chemical is used to remove the remaining photoresist, which also removed the iron that sits on top of photoresist. This leaves the pattern in iron on the alumina coated silicon wafer.

The carbon nanotubes are grown on the wafer by passing ethylene and hydrogen gases over the wafer at $750{ }^{\circ} \mathrm{C}$. Carbon infiltration is performed by passing argon and ethylene gasses over the wafer at $900{ }^{\circ} \mathrm{C}$. Growth and infiltration must take place for the proper amount of time to grow the mechanisms to the desired out-of-plane width of the hinge. Once completed, the hinges are removed from in between the support structures and are isolated for deflection testing and imaging. Prototypes CNT-1 and CNT-2 are shown in Figure 27. CNT-1 was capable of $90^{\circ}$ of deflection. A scanning electron micrograph shows CNT-1 deflected to $90^{\circ}$ in Figure 28.

CNT-2 experienced brittle failure during deflection. While deflecting CNT-2, axial loading was inadvertently induced on the hinge and failure was possibly due to off-axis stresses combined with the stresses predicted during rotation. The material properties used to predict the stresses were shown in Table 5 but are only estimates and could help account for the failure.

Another possible cause for failure of the smaller design (CNT-2) is that the flexure thickness after fabrication for both prototypes was thicker than designed due to inaccuracies in the photolithography exposure time. The flexures for the larger design (CNT-1) were measured to be approximately $43 \mu \mathrm{m}$ thick instead of $30 \mu \mathrm{m}$ as designed. The increase in thickness for 


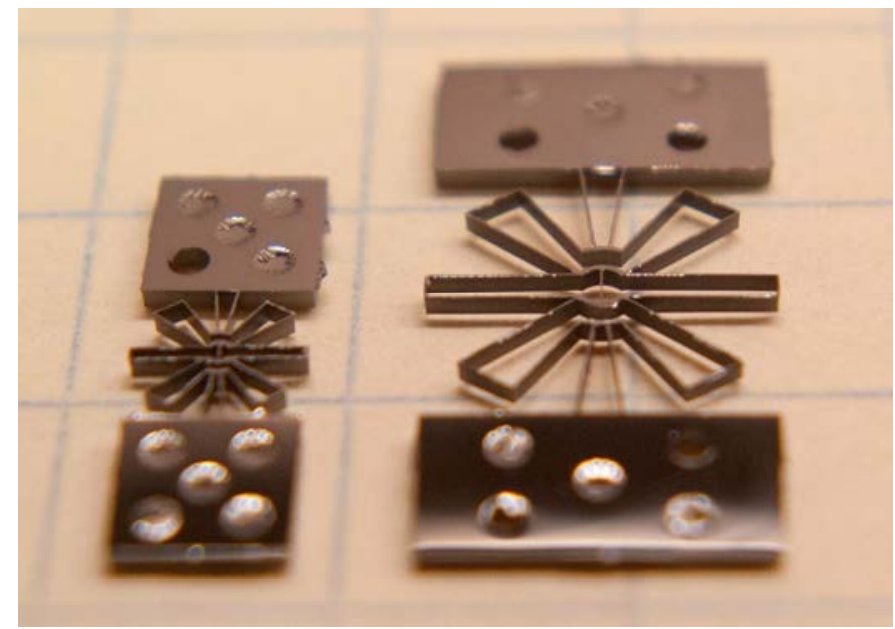

Figure 27: Prototypes CNT-1 and CNT-2.

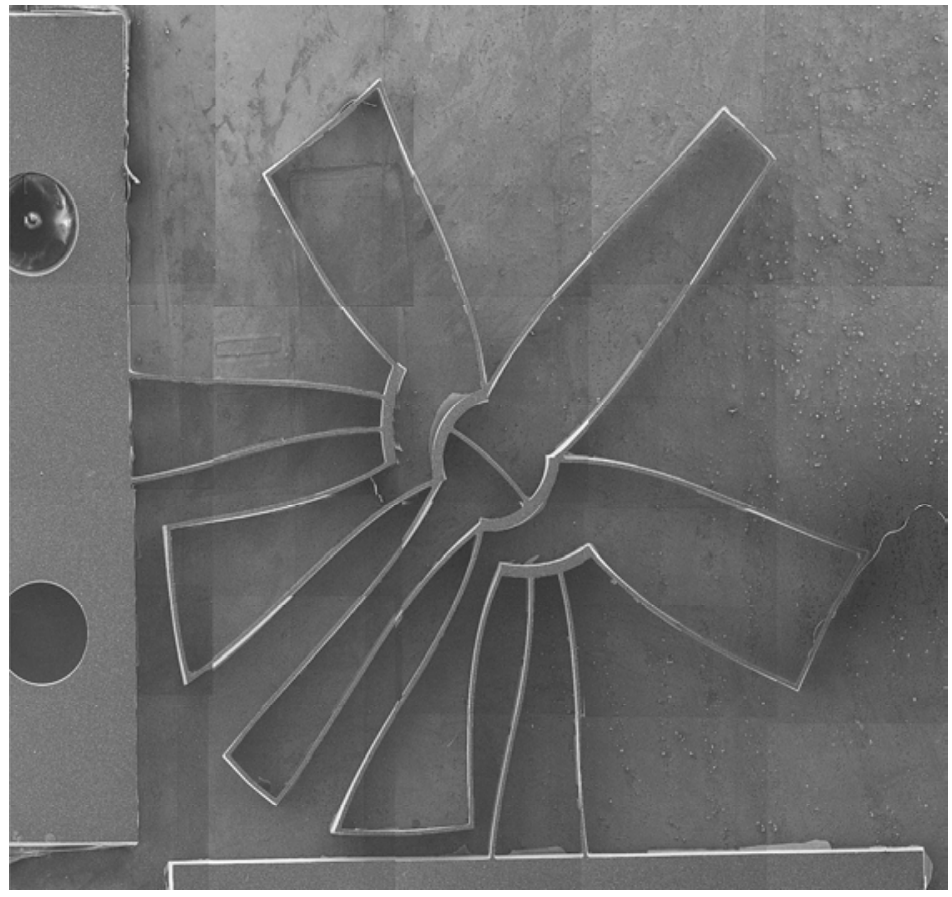

Figure 28: A composite scanning electron micrograph of CNT-1 deflected to $90^{\circ}$. 
CNT-2 would be the same since photolithography, growth, and infiltration occured at the same time for both.

The fabricated thickness of CNT-1 was input into the ANSYS model and solved. It predicted a maximum von Mises stress of $42.6 \mathrm{MPa}$ (up from 30.0 $\mathrm{MPa}$ as predicted in Table 4 using a thickness of $30 \mu \mathrm{m}$ ), which is still below the yield stress, and this is supported by the fact that it did not break when deflected. The brittle failure of CNT-2 was likely due to a combination of increased flexure thickness and off-axis stresses.

\section{Flex-16 Fabrication and Application}

\subsection{Manufacturability}

The Flex-16 benefits from the ability to be fabricated using planar manufacturing processes including:

- CNC milling (used for PP-1 \& PP-2)

- Wire EDM

- Electron Beam Manufacturing (used for Ti-1)

- Direct Metal Laser Sintering Rapid Prototyping

- MEMS Fabrication Processes (used for CNT-1 \& CNT-2)

It could also be stamped from thin metal sheets which could be subsequently bolted together. These options are lower cost alternatives compared to the manufacturing methods often used for more complex space mechanisms.

\subsection{Material Selection}

Table 11 identifies four possible candidate materials for compliant space mechanisms and shows a relative comparison of their strength, temperature resistance, fatigue resistance, and strength-to-modulus ratio. The temperature resistance is based on their coefficient of thermal expansion.

Each material has its own unique advantages and challenges. The specific application should be considered carefully when selecting a material. 
Table 11: Candidate materials for compliant space mechanisms

\begin{tabular}{|c|c|c|c|c|}
\hline Material & Strength & $\begin{array}{l}\text { Temperatur } \\
\text { Resistance }\end{array}$ & $\begin{array}{l}\text { Fatigue } \\
\text { Resistance }\end{array}$ & $\begin{array}{l}\text { Strength- } \\
\text { to- } \\
\text { Modulus }\end{array}$ \\
\hline Inconel & Low & High & Poor & Poor \\
\hline Titanium & High & Fair & Poor & Fair \\
\hline Nitinol & Fair & Fair & High & Fair \\
\hline Elgiloy & High & High & Fair & Fair \\
\hline
\end{tabular}

\subsection{Flex-16 Ti-2: A Compliant Space Deployment Hinge Example}

A Flex-16 hinge is designed to meet typical requirements from the space industry and is shown conceptually integrated into a spacecraft deployment hingeline in Section 10.4.

Suppose we want to design a deployment hinge to allow for $90^{\circ}$ of rotation using two Flex-16s in parallel on the hingeline and a constant torque spring as the source of torque. The torque losses across the hingeline are summed to determine the amount of torque required at $90^{\circ}$ in the Flex-16s and the torque required in the constant torque spring. This will then allow us to design the Flex-16 to have the proper stiffness.

The typical torque loss across a hingeline comes from several sources. The following are typical estimated torque losses in in-lb for a typical current hingeline components: Harness 23, Damper 2, Latch 3, and Bearings 2. This sums to around 30 in-lb torque loss across the hingeline. The factor of safety design requirement for most conceptual design reviews is 2.75 [25]. This brings the required torque on the hingeline to $82.5 \mathrm{in}-\mathrm{lb}$. This is the torque that the constant torque spring or torsional spring will be required to produce. There will be two hinges on the hingeline which must allow for a $90^{\circ}$ deployment. This means the hinges combined must produce 30 in-lb of torque at $90^{\circ}$. Each hinge needs to produce 15 in-lb at $90^{\circ}$ since they are used in parallel.

A Flex-16 design was created out of titanium to meet this requirement by using the same analysis methods as the other designs and can be described by the parameters in Table 12. The design has the torque-displacement relationship shown in Figure 30 and can be seen to have a torque of approximately $15 \mathrm{in}-\mathrm{lb}$ at $90^{\circ}$. The stiffness of the hinge is $9.535 \mathrm{in}-\mathrm{lb} / \mathrm{rad}(1.0773 \mathrm{Nm} / \mathrm{rad})$.

The predicted stress and displaced shape are shown in Figure 30. The 
Table 12: Ti-2 example design parameters

\begin{tabular}{|cl|}
\hline Parameter & Value \\
\hline $\mathrm{R}$ & $.0787 \mathrm{~m}$ \\
$\mathrm{t} 1$ & $0.7 \mathrm{~mm}$ \\
$\mathrm{t} 2$ & $3.0 \mathrm{~mm}$ \\
$\mathrm{w}$ & $1.27 \mathrm{~cm}$ \\
\hline $\mathrm{al}$ & $7^{\circ}$ \\
$\mathrm{a} 2$ & $22^{\circ}$ \\
$\mathrm{a} 3$ & $34^{\circ}$ \\
$\mathrm{a} 4$ & $45^{\circ}$ \\
$\mathrm{a} 5$ & $56^{\circ}$ \\
$\mathrm{a} 6$ & $57^{\circ}$ \\
$\mathrm{a} 7$ & $85^{\circ}$ \\
$\mathrm{a} 8$ & $90^{\circ}$ \\
\hline $\mathrm{f}$ & 1.05 \\
$\mathrm{f} 2$ & 0.29 \\
$\mathrm{f} 3$ & 0.94 \\
$\mathrm{f} 4$ & 1.25 \\
$\mathrm{f} 5$ & 0.95 \\
$\mathrm{f} 6$ & 1.0 \\
$\mathrm{f} 7$ & 0.15 \\
$\mathrm{f} 8$ & 1.0 \\
\hline
\end{tabular}




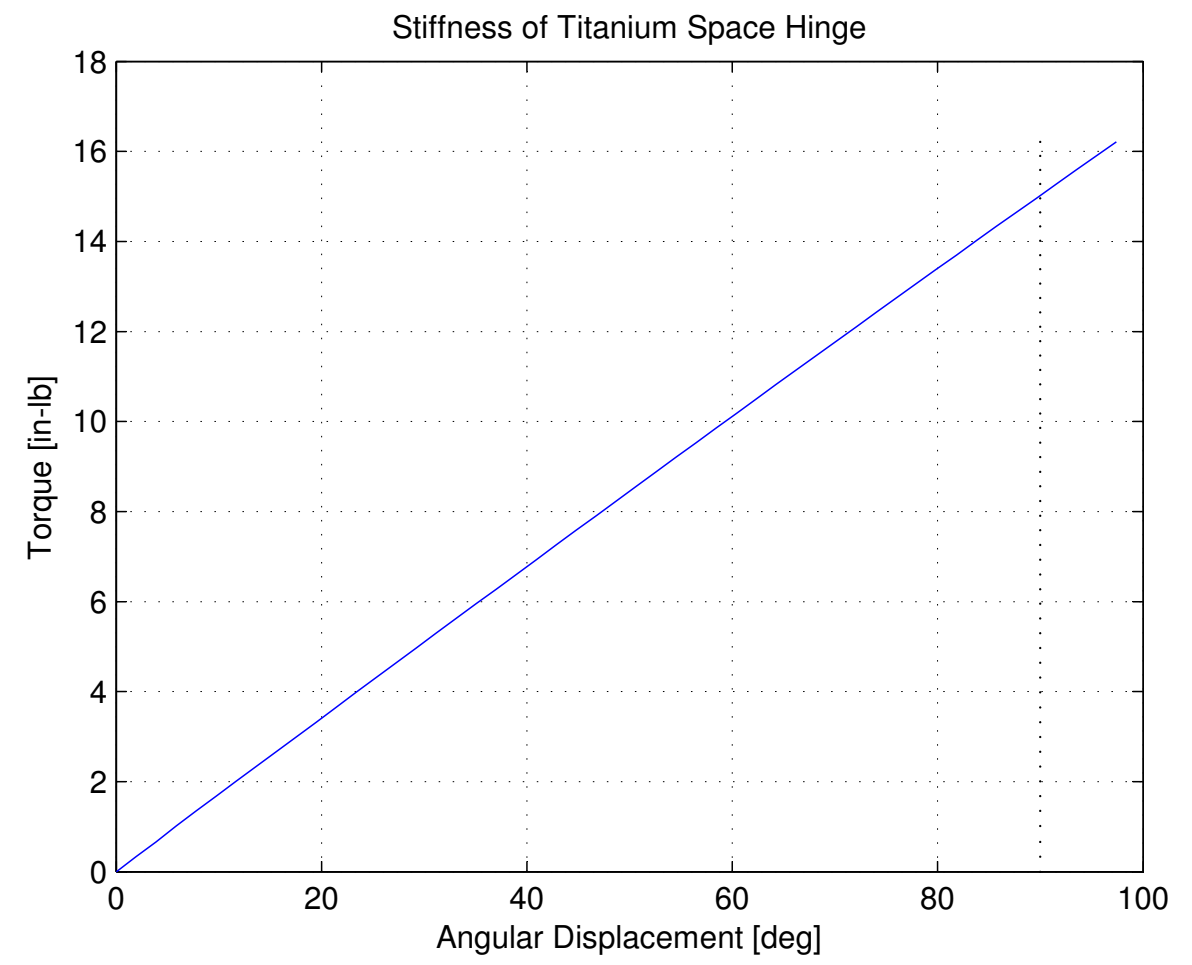

Figure 29: Ti-2 predicted stiffness. 


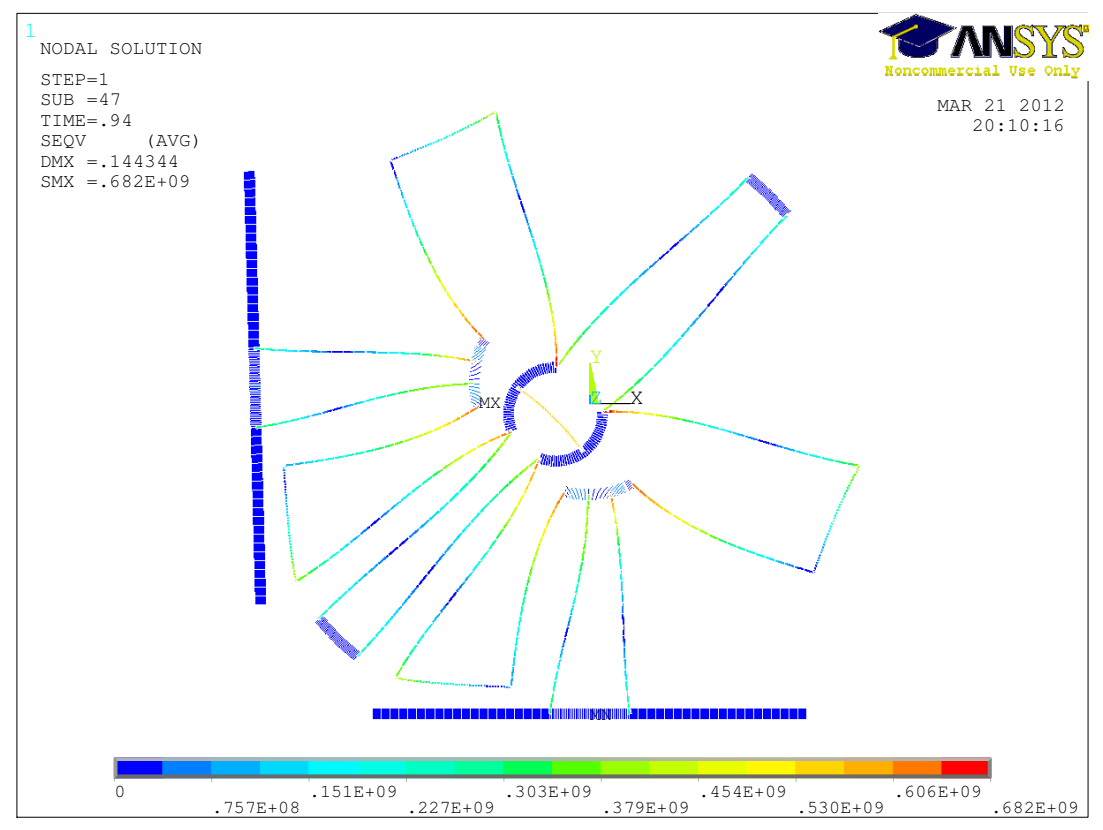

Figure 30: Ti-2 predicted stress and displaced shape. 
maximum von Mises stress is predicted to be $682 \mathrm{MPa}$, which is less than the yield strength of $827 \mathrm{MPa}$ used in this analysis. The Flex-16 design meets the requirements.

\subsection{Spacecraft Integration}

The Flex-16 is intended for future application as a compliant spacecraft deployment hinge where specific torque requirements are applied to the mechanism. Different configurations of the Flex-16 have been proposed that provide options when designing for this application. The hinge can be used in

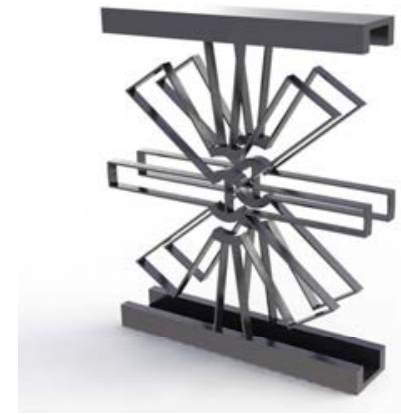

(a) Flex-16 parallel configuration

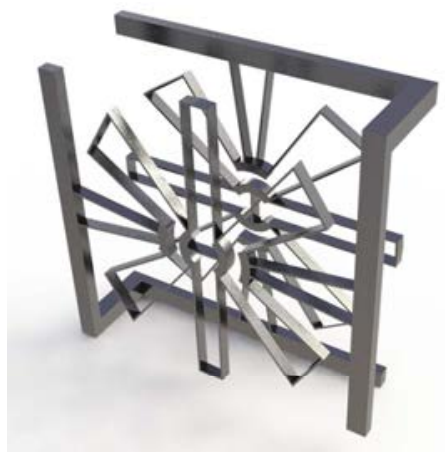

(b) Flex-16 $90^{\circ}$ offset configuration

Figure 31: Two configurations of combined Flex-16s. These configurations can be used to tailor the stiffness to meet specific torque requirements or to alleviate off-axis stiffness problems.

different configurations in a modular manner. Figure 31(a) shows two Flex$16 \mathrm{~s}$ in parallel. This may be used to increase the stiffness for higher torque applications while still allowing for planar manufacturing and reasonable material thicknesses. Figure 31(b) shows two hinges in parallel, offset from each other by $90^{\circ}$. These configurations could be used to improve off-axis stiffness and minimize undesirable vibrations.

The hinge can be integrated into the bracketry that attaches it to the spacecraft as depicted in Figure 32(a). The hinge can be integrated with a constant torque spring to allow actuation, as depicted in Figure 32(b). Two hinges with integrated bracketry would attach to a deploying panel in a manner similar to Figure 33 . 


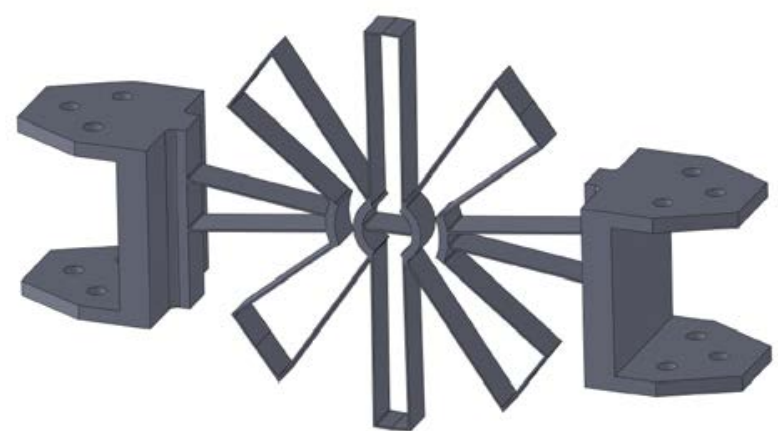

(a) Flex-16 integrated with brackets.

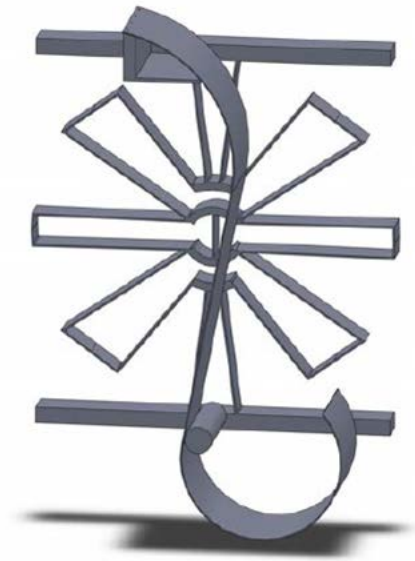

(b) Flex-16 integrated with a constant torque spring.

Figure 32: Two possible integrations of the Flex-16. The hinge can be integrated with the spacecraft using brackets. A constant torque spring can provide actuation.

\section{Conclusions}

\subsection{Strengths of the Flex-16}

The Flex-16 demonstrates desirable performance and has potential for application in space and other applications. While its intended application is as a compliant spacecraft deployment hinge, it is well-suited for non-space applications as a compliant revolute joint replacement. The strengths and challenges associated with the Flex-16 are listed here.

The strengths of the Flex-16 design are:

- Large-displacement hinge capable of $90^{\circ}$ of rotation

- Monolithic, simplified manufacturing

- Compact and lightweight

- Nearly linear stiffness over range of motion

- Customizable stiffness possible for various torque applications

- Elimination of lubrication, friction, backlash, and contact surfaces 


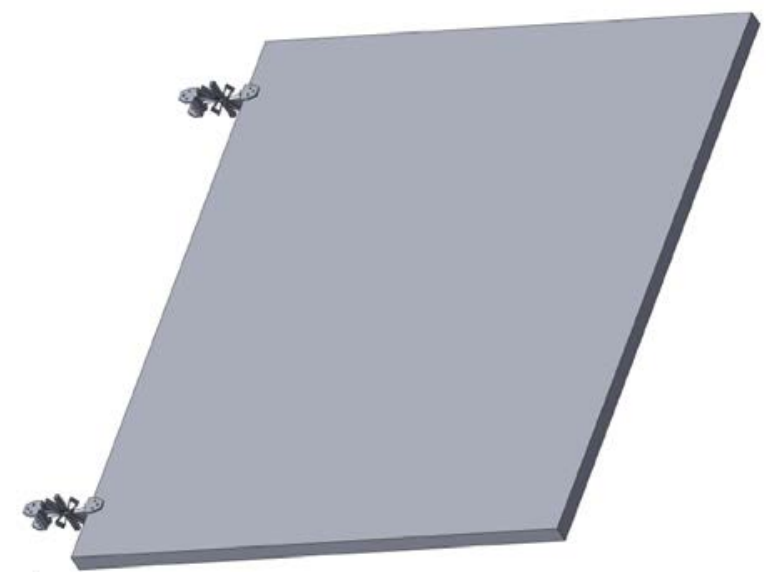

Figure 33: Two Flex-16s integrated with a solar array panel.

- Can be integrated with spacecraft and current components

- Analytically predictable torque vs angular displacement behavior

The Flex-16 presents large displacement capability from a monolithic compliant mechanism. The ability to parametrically model and predict the nonlinear stiffness, displaced shape, and stress over the full range of motion will allow the designer to more readily design a deployment hinge to meet design requirements. The nearly linear stiffness of the Flex-16 makes it easy to approximate a linear stiffness in the deployment dynamics model. The benefit of monolithic construction is the ability to manufacture the hinge from a planar material with a simple milling or similar process. This can help to reduce manufacturing time and costs. The hinge can be made compact to fit within the small size envelopes of launch. The hinge is able to be reset, be installed, replaced, or removed, used modularly, used in series or parallel for redundancy or axis alignment, fitted with a latch or brackets or torque application devices, etc. This allows for flexibility in the assembly, integration, and testing phase of a spacecraft lifecycle.

\subsection{Challenges of the Flex-16}

The challenges of the Flex-16 design are:

- Low off-axis stiffnesses (axial and out-of-plane bending) leading to vibration problems 
- Parasitic center shift if not taken into account

- Possible creep and stress relaxation if stowed in deflected position

The off-axis stiffness, axially and out-of-plane bending, are both a problem but can be alleviated by having two or more hinges in parallel on a hingeline or by widening the out of plane dimension of the hinge. The off-axis stiffness will also result in challenges with launch vibrations and further work may need to be done to stiffen the hinge so the fundamental natural frequency is above the design requirement. If the hinge is designed to be stowed in the deflected position, creep can occur. Proper design of the hinge and bracketry allow the hinge to be in the undeflected state during stow and launch configurations. The parasitic center shift will affect pointing or deployment accuracy and should be quantified.

The Flex-16 design was demonstrated in five prototypes and three different materials and manufacturing processes and presents a promising design as a monolithic large-displacement compliant deployment hinge.

\section{Acknowledgments}

I would like to thank Garrett Aida, the undergraduate researcher who helped develop the parametric CAD model and investigate material properties. I would like to thank Jason Lund, the undergraduate researcher who helped me fabricate the carbon nanotube framework prototypes and image them on the scanning electron microscope. I would like to thank Kevin Cole, the mechanical equipment manager at BYU, for his help in testing the prototypes. I would like to thank Ken Forster, the projects lab supervisor at $\mathrm{BYU}$, for his help in prototyping on the CNC mill.

I would like to acknowledge Lockheed Martin Space Systems for their help in defining the research direction that led to the development of the Flex-16. Specifically, I would like to acknowledge Tom Pawlowski for his assistance in organizing the compliant space mechanisms seminar in June 2011 at Lockheed Martin Space Systems that led to the selection of a compliant deployment hinge for space as the desirable next step in space mechanism advancement.

I would like to thank Dr. Brian Trease and Dr. Greg Agnes of NASA Jet Propulsion Laboratory for their support and excitement in this research.

I would like to gratefully acknowledge NASA Marshall Space Flight Center and Dr. Jonathan Jones for their collaboration in fabricating the Flex-16 
Ti-1 prototype out of titanium using the electron beam manufacturing metal rapid prototyping process.

This material is based upon work supported by the National Science Foundation under Grant No. CMMI-0800606. Any opinions, findings, and conclusions or recommendations expressed in this material are those of the authors and do not necessarily reflect the views of the National Science Foundation.

\section{References}

[1] W. Shapiro, F. Murray, R. Howarth, NASA Space Mechanisms Lessons Learned Study, volume 1-Summary, NASA Lewis Research Center Cleveland, Ohio TM 107046, 1995.

[2] R. M. Fowler, L. L. Howell, S. P. Magleby, Compliant space mechanisms: A new frontier for compliant mechanisms, Journal of Mechanical Sciences 2 (2011) 205-215.

[3] L. L. Howell, Compliant Mechanisms, John Wiley \& Sons, Inc., 2001.

[4] S. T. Smith, Flexures: Elements of Elastic Mechanisms, CRC Press, 2000 .

[5] N. Lobontiu, Compliant Mechanisms: Design of Flexure Hinges, CRC Press, 2003.

[6] J. B. Hopkins, M. L. Culpepper, Synthesis of precision serial flexure systems using freedom and constraint topologies (fact), Precision Engineering 35 (2011) 638-649.

[7] H. Zhao, S. Bi, J. Yu, Nonlinear deformation behavior of a beam-based flexural pivot with monolithic arrangement, Precision Engineering 35 (2011) 369-382.

[8] X. Pei, J. Yu, G. Zong, S. Bi, H. Su, The modeling of cartwheel flexural hinges, Mechanism \& Machine Theory 44 (2009) 1900-1909.

[9] S. E. Wilding, L. L. Howell, S. P. Magleby, Spherical lamina emergent mechanisms, Mechanism and Machine Theory 49 (2012) 187-197. 
[10] M. Callegari, A. Cammarata, A. Gabrielli, M. Ruggiu, R. Sinatra, Analysis and design of a spherical micromechanism with flexure hinges, Journal of Mechanical Design 131 (2009) 051003-11.

[11] S. E. Wilding, L. L. Howell, S. P. Magleby, Introduction of planar compliant joints designed for compressive and tensile loading conditions in lamina emergent mechanisms, Mechanism and Machine Theory in press (2012).

[12] J. S. Dai, J. R. Jones, Mobility in metamorphic mechanisms of foldable/erectable kinds, Journal of Mechanical Design, Transactions of the ASME 121 (1999) 375-382.

[13] W. Yao, F. Cannella, J. S. Dai, Automatic folding of cartons using a reconfigurable robotic system, Robotics and Computer-Integrated Manufacturing 27 (2011) 604-613.

[14] E. Pernette, S. Henein, I. Magnani, R. Clavel, Design of parallel robots in microrobotics, Robotica 15 (2011) 417420.

[15] R. J. Wood, S. Avadhanula, R. Sahai, E. Steltz, R. S. Fearing, Microrobot design using fiber reinforced composites, Journal of Mechanical Design 130 (2008) 052304-11.

[16] B. P. Trease, Y.-M. Moon, S. Kota, Design of large-displacement compliant joints, Journal of Mechanical Design 127 (2005) 788-798.

[17] S. Krishnan, L. Saggere, Design and development of a novel micro-clasp gripper for micromanipulation of complex-shaped objects, Sensors and Actuators A: Physical 176 (2012) 110-123.

[18] A. M. Watt, S. Pellegrino, Tape-spring rolling hinges, in: Proceedings of the 36 Aerospace Mechanisms Symposium, Glenn Research Center.

[19] H. M. Y. C. Mallikarachchi, S. Pellegrino, Optimized Designs of Composite Booms with Integral Tape-Spring Hinges, Technical Report, American Institute of Aeronautics and Astronautics, 2010.

[20] H. M. Y. C. Mallikarachchi, S. Pellegrino, Quasi-static folding and deployment of ultrathin composite tape-spring hinges, Journal of Spacecraft and Rockets 48 (2011) 187-198. 
[21] A. Pellerin, T. Mazoyer, D. Givois, J. Sicre, G. Begoc, Antenna Deployments: A Self-Motorised Hinge, Technical Report, Metravib Rds Company and CNES, 2002.

[22] S. Henein, P. Spanoudakis, S. Droz, L. I. Myklebust, E. Onillon, Flexure pivot for aerospace mechanisms, in: 10th European Space Mechanisms and Tribology Symposium, pp. 285-288.

[23] M. Svensson, MSV061 - Material properties of EBM-manufactured Ti6Al4V and Ti6Al4V-ELI, Technical Report, Arcam AB; obtained from NASA Marshall Space Flight Center, 2009.

[24] D. Hutchison, Q. Aten, B. Turner, N. Morrill, L. Howell, B. Jensen, R. Davis, R. Vanfleet, High aspect ratio microelectromechanical systems: A versatile approach using carbon nanotubes as a framework, in: Solid-State Sensors, Actuators and Microsystems Conference, 2009. Transducers 2009. International, pp. $1604-1607$.

[25] AIAA, Aiaa s-114, moving mechanical assemblies for space and launch vehicles, 2005. 